\title{
Global Epidemiology and Genetic Environment of $m c r$ genes: A One Health Systematic Review of Current and Emerging Trends
}

\author{
Masego Mmatli ${ }^{\mathrm{a}}$, Nontombi Marylucy Mbelle ${ }^{\mathrm{a}}$, John Osei Sekyere*abc
}

${ }^{\mathrm{a}}$ Department of Medical Microbiology, School of Medicine, University of Pretoria, South Africa.

${ }^{\mathrm{b}}$ Department of Microbiology \& Immunology, Indiana University School of Medicine-Northwest, USA

${ }^{\mathrm{c}}$ Department of Dermatology, School of Medicine, University of Pretoria, South Africa

\#Address correspondence to Dr. John Osei Sekyere, Department of Medical Microbiology, School of Medicine, University of Pretoria, 0084 Pretoria, South Africa: 1 j.oseisekyere@up.ac.za; joseisek@iu.edu

Running title: $M c r-1$ : the dawn of Pandrug resistance.

Tweet: "Within bacteria, mobile colistin resistance genes have spread widely, with a high incidence in human samples. It's critical to comprehend the genetic tools facilitating this spread and their mechanisms of action. These are detailed in this paper, as are new therapeutic strategies for managing these resistance genes."

\section{Importance/Highlights}

- Mcr genes are associated with mobile genetic elements that are facilitating its global dissemination.

- Using colistin as a growth promoter increases the risk of acquiring mcr-positive Enterobacteriaceae in food-producing animals.

- There is a higher incidence of $m c r$ genes in humans than animals.

- MCR proteins are phosphoethanolamine (PEtN) transferases that mediate the transfer of PEtN from its primary phosphatidylethanolamine to lipid A.

- Multiple compounds can synergistically restore colistin's activity, reducing its dosage and toxicity.

- CRISPR-Cas9, endolysins-engineered enzymes, and antimicrobial peptides are promising therapies for colistin resistance 
medRxiv preprint doi: https://doi.org/10.1101/2022.02.28.22271560; this version posted March 1, 2022. The copyright holder for this preprint (which was not certified by peer review) is the author/funder, who has granted medRxiv a license to display the preprint in perpetuity.

It is made available under a CC-BY-NC-ND 4.0 International license .

\section{Abstract}

31 Background: Mobile colistin resistance ( $m c r$ ) genes modify Lipid A molecules of the

32 lipopolysaccharide, changing the overall charge of the outer membrane.

33 Methods: A systematic review of all studies published between January 2015 to July 2021

34 was performed. Included articles described $m c r$ genes in the context of their genetic 35 environment, fitness cost, crystal structure, their enzymatic activity and the risk factors 36 associated with the acquisition of $m c r$. Studies describing the epidemiology of $m c r$ genes and novel therapeutics were included.

Results and Discussion: Ten $m c r$ genes have been described to date within eleven Enterobacteriaceae species, with Escherichia coli, Klebsiella pneumoniae, and Salmonella species being the most predominant. They are present worldwide in 72 countries, with human specimens currently having the highest incidence. This is due to the wide dissemination of $m c r$ in livestock animals, meat, manure, the environment, and wastewater samples, increasing the risk of transmission via foodborne, zoonotic, and vector-borne routes to humans. The stability and spread of $m c r$ genes were mediated by mobile genetic elements such as the $\mathrm{IncHI}_{2}$ conjugative plasmid, which is associated with multiple $m c r$-variants and other antibiotic resistance genes. The cost of acquiring $\mathrm{mer}$ is reduced by compensatory adaptation mechanisms. MCR proteins are well conserved via structurally. Hence, MCR-1 inhibitors and therapeutics should be applicable to all MCR proteins.

Conclusion: $M c r$ genes have spread from animals into the clinical setting, threatening public health. Combination therapies are a promising option for managing and treating colistinresistant Enterobacteriaceae isolates whilst reducing the toxic effects of colistin.

Keywords: colistin resistance; polymyxins; crystal structure; MCR activity; risk factors; Enterobacteriaceae.

55 Colistin was first introduced into clinical practice in the $1950 \mathrm{~s}^{1}$. It was derived from Bacillus 56 polymyxa and belongs to polymyxins ${ }^{2}$, a family of cationic polypeptide antibiotics with 57 broad-spectrum antimicrobial activity ${ }^{3}$. Colistin has a bactericidal effect on Gram-negative 58 bacteria and thus is used for treating Gram-negative bacterial infections 1, 2. Cationic 59 polypeptides have a high electrostatic attraction to the anionic lipopolysaccharide (LPS) 60 located on the outer membrane of Gram-negative bacteria. There, it displaces the magnesium 
61 and calcium divalent cations $\left(\mathrm{Mg}^{2+}\right.$ and $\left.\mathrm{Ca}^{2+}\right)$, which stabilise the LPS molecules ${ }^{1,2}$. This

62 results in the disruption of the cell's permeability, leading to cell death. However, due to the 63 adverse side effects such as nephrotoxicity and neurotoxicity seen during colistin therapy ${ }^{2}$, in 64 the early 1980s, it was removed from human use and administered to food-producing animals 65 as a growth promoter and therapeutics ${ }^{1,4}$. With the increasing resistance caused by Gram66 negative pathogens such as carbapenem-resistant Enterobacteriaceae that threatens global 67 public health ${ }^{5}$, colistin was recently reintroduced as a last-line treatment option ${ }^{3,4,6}$.

68 Colistin resistance was largely associated with chromosomal-encoded mechanisms that involved two component systems (TCSs) such as $p m r A B$ and $p h o P Q$, and mutation(s) in the $m g r B$ regulator in Klebsiella pneumoniae ${ }^{7-9}$. These chromosomal mutations mediated colistin resistance by modifying LPS, changing LPS's overall charge, and reducing the affinity of polymyxins to the outer membrane ${ }^{7-9}$. The types of modifications seen include the addition of phosphoethanolamine (PEtN) and 4-amino-4-deoxy-L-arabinose (Ara4N) to the 1phosphate or 4-phosphate groups of Lipid A, respectively ${ }^{10}$. The PEtN modification is associated with the $p m r A B$ TCSs and the Ara4N modification with the $p h o P Q$ TCS alongside the $\operatorname{mgr} B$ regulator ${ }^{10}$.

Plasmid-mediated colistin resistance ( $\mathrm{mcr}$ ) gene was first identified in both animals and humans by Liu et al. (2016) ${ }^{11}$ from an Enterobacteriaceae. mcr-1 increased colistin resistance and encoded a PEtN transferase enzyme that added PEtN to Lipid A ${ }^{11}$ at the 4'phosphate group ${ }^{12,13}$. The MCR-1 PEtN transferase enzyme had similar structural properties to EptC and LptA PEtN transferases from Campylobacter jejuni and Neisseria meningitidis, respectively ${ }^{14,15}$. The lipid A modification is identifiable with a matrix-assisted laser desorption/ionization-time of flight (MALDI-TOF) mass spectrometry (MS) assay with an additional $\mathrm{m} / \mathrm{z}=1920.5$ peak observed in $\mathrm{mcr}$-producing isolates, representing the modified Lipid A molecule ${ }^{16}$. This activity is seen across the different $m c r$ variants: $m c r-2$ to $m c r-10$.

After the discovery of $m c r-1$, other novel $m c r$ variants i.e., $m c r-2$ to $m c r-10$, which are widely distributed within Enterobacteriaceae, have been reported globally. The identification of the mcr- 1 gene and its variants, mcr-2 to mcr-10, is largely mediated by PCR screening and whole genome sequencing (WGS) tools, which are also used in $\mathrm{mcr}$ surveillance programmes 11, 17-21. Each $m c r$ variant is mostly located on conjugative plasmids, associated with mobile genetic elements (MGEs), and mediates colistin resistance through PEtN transferase activity. mcr are widely distributed within Enterobacteriaceae, including Escherichia coli, $K$. 
medRxiv preprint doi: https://doi.org/10.1101/2022.02.28.22271560; this version posted March 1, 2022. The copyright holder for this preprint (which was not certified by peer review) is the author/funder, who has granted medRxiv a license to display the preprint in perpetuity.

It is made available under a CC-BY-NC-ND 4.0 International license .

93 pneumoniae, Salmonella species, and Enterobacter species, ${ }^{3,11,22,23}$ and have also been 94 reported within other Gram-negatives such as Pseudomonas aeruginosa and Acinetobacter 95 species ${ }^{24-26}$.

96 Initially, food-producing animals were the reservoir of $\mathrm{mcr}$ genes due to the high usage of colistin in livestock ${ }^{11,27,28}$. Farmers' consumption of livestock and/or contact with livestock or their faeces was found to be a risk factor for infection with an $m c r$-producing isolate ${ }^{28,29}$. Global screening of $m c r-1$ genes in livestock found increased number of $m c r$-producing isolates, resulting in a ban of colistin in food-producing animals for both growth promotion and treatment of bacterial infections ${ }^{30,31}$. The World Health Organisation (WHO), thereafter, listed colistin as part of the critically important antimicrobials for human medicine. This was to help preserve the effectiveness of colistin for clinical use and to minimize the transmission of $m c r$ genes from animals, livestock, and the environment to humans ${ }^{30,31}$.

Purpose of review

This review provides a map of the dissemination of $m c r-1$ and its variants. It further evaluates the genomic content of each mcr variant, identifying the possible progenitor and the mobile elements that each is associated with. We largely look at the $m c r-1$ gene, its structure and function, which enables it to mediate colistin resistance, the fitness cost imposed by $m c r-1$ expression, and the risk factors enabling the dissemination of $m c r$ genes. The review further summarizes the possible treatment options for $m c r$-producing colistin-resistant isolates.

Herein, we highlight the epidemiology and evolution of $m c r$ genes over the last 6 years by providing insight into the genomic content of each variant, identifying MGEs that aid in its dissemination, their global distribution, the crystal structure, and enzymatic activity of MCR proteins, and promising emerging therapeutics that could manage mcr-positive Enterobacteriaceae infections.

\section{Methods}

118 A comprehensive literature search was performed using PubMed. Journal articles published in English within the last six years (January 2016 to July 2021) were retrieved and screened using the following keywords: "colistin resistan*" or "polymyxin resistan*" and "mcr*" and "Enterobacteriaceae". The search was focused on journal articles that discussed the crystal structure of MCR enzymes and their enzymatic activity, the genetic environment and genetic support (MGEs) of mor genes, as well as their molecular epidemiology, risk factors and 
medRxiv preprint doi: https://doi.org/10.1101/2022.02.28.22271560; this version posted March 1, 2022. The copyright holder for this preprint (which was not certified by peer review) is the author/funder, who has granted medRxiv a license to display the preprint in perpetuity.

It is made available under a CC-BY-NC-ND 4.0 International license .

124

125

126

127

128

129

130

131

132

133

134

135

management. However, studies that involved reviews, books and documents, case reports, case studies were excluded. The inclusion and exclusion protocol used in this review is seen in Figure 1. The data that was extracted from the included studies is found in Table S1.

\section{Results}

\section{Characteristics of included studies}

The study included 693 articles describing the epidemiology of $m c r$ genes, the crystal structure and enzymatic activity of MCR proteins, the genomic environment of each $\mathrm{mcr}$ gene, the risk factors associated with the acquisition of $m c r$-positive Enterobacteriaceae isolates and the novel therapeutic options that can be explored for managing $\mathrm{mcr}$-positive Enterobacteriaceae-related infections. A total of 429 articles were included in the epidemiological data and were used for the statistical analysis. The following data was extracted from the epidemiology articles: country, study year, specimen type and source, bacterial species, clone/MLST, mcr-type, mobile genetic elements (MGEs) and antibiotic resistance genes (ARGs) (Table $\mathrm{S} 1$ ).

\section{Enterobacteriaceae species distribution}

mcr genes are well disseminated within Enterobacteriaceae, being frequently identified within E. coli, $K$. pneumoniae and Salmonella species, in that order. Other Enterobacteriaceae species that have been identified with $m c r$ genes include Cronobacter species, Citrobacter species, Kluyvera species, Leclercia species, Raoultella ornithinolytica, and Shigella species (Figure 2A).

Initially, $m \mathrm{cr}$ genes were commonly identified in animals. However, after evaluating the number of reports collected from 2016 to 2021, the most common source of mcr-positive Enterobacteriaceae isolates was human specimens (Figure 2a). In human specimens, mcr genes are frequently isolated from Enterobacter sp., K. pneumoniae, Leclercia sp., and Shigella sp (Figure 2b). E. coli is the most common mcr-positive isolate and is usually isolated from animal specimens (Figure 2c); this is also seen with $R$. ornithinolytica, Salmonella sp., and S. Typhimurium (Figure 2b). Other sources identified include food and the environment, which are mostly made up of wastewater samples. In the environment, mcrpositive isolates comprised only three species: E. coli, K. pneumoniae, and Kluyvera sp (Table S2). Lastly, mcr-positive species have been also isolated from food animal and vegetable samples, being isolated from mostly packaged meat and vegetables. These species 
medRxiv preprint doi: https://doi.org/10.1101/2022.02.28.22271560; this version posted March 1, 2022. The copyright holder for this preprint (which was not certified by peer review) is the author/funder, who has granted medRxiv a license to display the preprint in perpetuity.

It is made available under a CC-BY-NC-ND 4.0 International license .

155 include: Cronobacter sp., Enterobacter sp., E. coli, K. pneumoniae, Salmonella, and S. 156 Typhimurium.

157

158

159

160

161

162

163

164

165

166

167

168

169

170

171

172

173

174

175

177

178

179

180

181

182

183

184

185

186

Mcr-1 and its variants are the most common and well disseminated of all $\mathrm{mcr}$ variants (Figure 3a). This was later shown to be because of multiple factors such as fitness cost and MGEs. Mcr-1 has spread globally and has been identified in 69 countries, with $m c r-1$ being the most prevalent mcr variant in most countries (Figure 3c). Although the other variants have spread globally, they have been identified in low numbers compared to mcr-1 (Figure 3a). This includes $m c r-3$, which has been identified in fifteen countries, with Colombia and Thailand having the highest counts. Mcr-3 variants (mcr-3.1, mcr-3.5, etc) have been identified in an additional three countries, and in a total of eight countries. This brings the total count of countries with $m c r-3$ genes to eighteen (Table S3, Figure 3c). Other well disseminated $m c r$ variants in low numbers includes $m c r-5$ and $m c r-9$, identified in ten countries. $m c r-8$ has been reported in seven countries, $m c r-4$ in five countries, $m c r-7$ and $m c r-10$ in two countries, and mcr-6 in Thailand only.

Amongst the 70 countries identified with $m c r$ genes, countries such as Thailand harboured six $m c r$-variants (mcr-1, mcr-3.mcr-6, mcr-7, mcr-8 and mcr-9) and China harboured eight variants (mcr-1, $m c r-3, m c r-4, m c r-5, m c r-7, m c r-8, m c r-9$ and $m c r-10)$. Other countries such as the USA, Turkey, Spain, Nigeria, Korea, Japan, Italy, France, England, Czech Republic, Cambodia, Brazil, Belgium, and Bangladesh harboured three to four $m c r$-variants, each inclusive of the $m c r-1$ variants (Figure 3b, Table S3). Most $m c r$ genes have been reported in studies from China (In Figure 3C), which is due to the large volumes of articles being published on mer epidemiology from China.

It has thereafter been seen in China, that clones within $m c r$-positive $E$. coli (MPEC), which includes ST744, ST410, ST10, ST43, ST101 and ST206, have been identified in all four sources: food, environment, animals, and humans, seen in Table S4. These clones have, however, also disseminated globally, where ST744 has been identified in humans in eleven countries, in food in five countries, in animals in five countries and in the environment only in China. The MPEC ST10 strain is the most widely distributed within E. coli. It has been identified in animals in seventeen countries, humans in sixteen countries, the environment in five countries, and in food in five countries. MPEC clones within each country are usually found in both animals and humans, seen with ST744, ST69, ST117, ST131 and ST354 in Italy. 
medRxiv preprint doi: https://doi.org/10.1101/2022.02.28.22271560; this version posted March 1, 2022. The copyright holder for this preprint (which was not certified by peer review) is the author/funder, who has granted medRxiv a license to display the preprint in perpetuity.

It is made available under a CC-BY-NC-ND 4.0 International license .

S. Typhimurium is also well distributed globally, with the $S$. Typhimurium ST34 strain identified in China, Colombia, Denmark, Germany, and the United Kingdom, in both animals and humans. In China, the S. Typhimurium ST34 strain has been identified in both humans and animals, and in food samples and human specimens in Germany. Similar results are seen in the monophasic variants of $S$. Typhimurium serovars (S.) 1,4,[5],12:i:-, and S. 4,[5],12:i:-, where ST34 was the only clone identified with $m c r$ genes. The S. 1,4,[5],12:i:- ST34 strain has only been identified in Portugal in animals, food and humans, and the S. 4,[5],12:i:- has been identified in Belgium, Canada, Italy, Switzerland and the United States in animals and humans (Table S4).

The direct transmission of $m c r$-positive Enterobacteriaceae (MCRPE) isolates from animals and humans is discussed in this review (See Risk factors) and the data seen in Table S4 highlights this route of transmission.

\section{Geographical and host distribution of clones and ARGs}

Similar to $\mathrm{mcr}$ genes (Figure 3c), other antimicrobial resistance genes (ARGs) are predominantly located in China (Figure 4), followed by Germany, Denmark, and England. Notably, several important ARGs are co-hosted by MCRPE isolates (Figure 3A). This is expected as colistin is used as a last-line antibiotic for multi-drug resistant (MDR) isolates. A Table showing the distribution of $m c r$-positive isolates hosting other ARGs is shown in Table S5.

\section{Plasmid incompatibility groups associated with mor genes}

Mcr genes are usually associated with insertion sequences (ISs), which aid in the mobilisation of resistance genes from the chromosome to plasmids and vice versa ${ }^{32}$. The dissemination of mor genes is, however, mediated by plasmids, which allow for the horizontal transfer and spread of resistance genes across different bacterial species, genera, and families ${ }^{33-35} . \mathrm{Mcr}$ genes have been identified with 41 different plasmid replicons, where eight of these are made up of $\mathrm{IncHI}_{2}$ or $\mathrm{IncHI}_{2 \mathrm{~A}}$. Most $m c r$ variants are associated with multiple incompatibility groups, with $m c r-1$ and its variants being associated with 37 plasmids; $\operatorname{IncI}_{2}, \operatorname{IncX}_{4}$ and $\mathrm{IncHI}_{2}$ were the most commonly reported (Figure 5). These incompatibility groups have also been shown to harbour other $m c r$ variants: $\mathrm{IncI}_{2}$ has been associated with $m c r-7$, IncX $\mathrm{X}_{4}$ with $m c r-2$, and $\mathrm{IncHI}_{2}$ with $m c r-9, m c r-3$, and its variants (Figure 5 and Table S6).

Interestingly, the broad-spectrum $\mathrm{IncHI}_{2}$ plasmid was associated with the most $\mathrm{mcr}$ variants and is thus the main driver of $m c r$ dissemination across different bacterial species. Further, 
medRxiv preprint doi: https://doi.org/10.1101/2022.02.28.22271560; this version posted March 1, 2022. The copyright holder for this preprint (which was not certified by peer review) is the author/funder, who has granted medRxiv a license to display the preprint in perpetuity.

It is made available under a CC-BY-NC-ND 4.0 International license .

219

220

221

222

223

224

225

226

227

228

229

230

231

232

233

234

235

236

237

238

239

240

241

242

243

244

245

246

247

248

249

$m c r-2, m c r-6$, and $m c r-7$ have only been identified in a single incompatibility group (Figure 5). This is because these $m c r$ variants have only been identified in low numbers. A heat map (Table S4) shows the MGEs profile of the included isolates, which includes both plasmid groups and IS elements.

\section{Discussion}

Since the emergence of $m c r-1$ in 2015 , it has spread from animals to humans through several sources and routes, mediated by chromosomal and plasmid borne mobile genetic elements. The genetic context, associated risk factors, protein structure, and enzymatic activity of each $m c r$ variant are discussed herein.

\section{Mcr-1 genomic content}

The $m c r-1$ gene is part of a 2,600 bp cassette that is made up of a putative promoter gene responsible for the expression of the $m c r-1$ gene and the hypothetical protein later identified as pap2 ${ }^{36,37}$. mcr-1 is speculated to have been derived from Moraxella species, which harbours the intrinsic chromosomal encoded mcr-like genes and the pap2 membraneassociated lipid phosphatase ${ }^{37,38}$. The pap2 gene is found in both $m c r-1$ and $m c r-2$ cassettes and shares $41 \%$ identity with Moraxella oloensis phosphatidic acid phosphatase 20,39 . Moraxella $m c r$-like genes with a significant degree of similarity to $m c r-1$ and $m c r-2$ in $M$. porci and M. osloensis were respectively identified in Genbank. Thus, these genes could be closely related ${ }^{38}$. Poirel et al. (2017a) identified an $m c r$-like gene, $m c r-2.2$, from an $M$. pluranimalium strain with an $82 \%$ and $99 \%$ amino acid identity to $m c r-1$ and $m c r-2$, respectively.

An analysis of $m c r-1$ sequences deposited in GenBank in 2017 revealed an $m c r-1.10$ variant from Moraxella sp. MSGI3-CO3 with $97.61 \%$ identity to the plasmid-borne $m c r-1$ gene. This isolate was isolated from the faecal contents of healthy pigs in the United Kingdom in April, $2014^{40}$. This data suggests that Moraxella species may have been the likely source of $m c r-1$ and $m c r-2^{37,39}$. Other evidence that supports the speculation that $m c r-1$ evolved from the Moraxella species is the identification of an ISApll element in M. bovoculi and M. porci ${ }^{39,41}$. Li et al. (2018) suggest ISApll integrated into M. bovoculi and thereafter evolved with the $m c r$-like genes to the point seen today. This synteny of mcr-pap2 genes across Moraxella species further highlights this genus as a natural reservoir of $m c r$-like genes and a possible progenitor due to the high amino acid identity ${ }^{38,39,42}$. 
medRxiv preprint doi: https://doi.org/10.1101/2022.02.28.22271560; this version posted March 1, 2022. The copyright holder for this preprint (which was not certified by peer review) is the author/funder, who has granted medRxiv a license to display the preprint in perpetuity.

It is made available under a CC-BY-NC-ND 4.0 International license .

250 The mobilization of the mcr-pap2 unit was thereafter accomplished through IS elements, but

251 Kieffer et al. (2017) identified a replicase gene associated with $m c r-1$ on IncX 4 plasmids. The

252 gene had a 99\% identity to M. lacunata, thus showing this species as a possible reservoir of

$253 \mathrm{IncX}_{4}$ plasmids and further speculating that the Moraxella family may encode genetic tools

254 likely involved in the initial mobilisation of $m c r$ genes ${ }^{38}$.

255 Stoesser et al. (2016) and Sun et al. (2018) suggested that the initial mobilisation of $m c r-1$

256 genes into Enterobacteriaceae was IS1294-mediated, using a one-ended rolling circle

257 transposition mechanism shown to be capable of mobilising adjacent sequences. The IS1294

258 may have mobilised the $m c r-1$ cassette into an ISApll composite transposon, creating an

259 ISApl1-mcr-1-pap2-IS1294-pap2-ISApl1 cassette, which has been identified on E. coli

260 chromosome ${ }^{32,43}$. It was found that the cassette was still flexible enough to jump from the

261 chromosome to a plasmid ${ }^{32}$ by generating a putative circular intermediate product.

262 There is increasing evidence, however, that the $m c r-1$ gene is mobilized primarily as a 263 composite transposon, Tn6330, that is made up of two copies of ISApll that bracket cassettes 26444,45 . ISApll is an IS that was first described in Acinetobacillus pleuropneumoniae and is part 265 of the IS30 family ${ }^{46}$. The IS elements of this family are flanked by 20-30-base pairs (bp) 266 inverted repeats (left IR (IRL), right IR (IRR)), which are essential for transposition ${ }^{47}$. The 267 IR contains a 924 bp open-reading frame that encodes a $44.3 \mathrm{kDa}$ transposase protein 268 containing a DDE domain, which encodes three conserved amino acid residues viz., $\mathrm{D}_{228 \text {, }}$ $269 \mathrm{D}_{295}$, and $\mathrm{E}_{648}(\mathrm{DDE})$, as well as carboxylase residues that help coordinate metal ions for catalysis 44, 47. Analysis of each ISApl1 element flanking the mcr-1-pap2 unit found conserved dinucleotides between the ISApl1 inverted repeats and the mcr-1-pap2 unit, an AT dinucleotide on the IRR of the upstream element and CG on the IRL of the downstream element ${ }^{44}$. An interesting observation in the $m c r-1.10$ variant identified in Moraxella sp. MSGI3-CO3 was the presence of these dinucleotides, AT upstream and CG downstream, flanking the $m c r-1$ structure ${ }^{40}$. These dinucleotides were suggested to represent the ancestral target-site duplications (TSDs) formed during the initial mobilisation of $m c r-1$ during ISApll insertion ${ }^{40}$. Therefore, Snesrud et al. (2018) suggested that the formation of the composite transposon, Tn6330, was through two independent insertion events of ISApll into the TArich region of the mcr-1-pap2 unit, generating the conserved interior 2bp TSDs, AT and CG target site but would retain both internal conserved 2 bp dinucleotides ${ }^{40}$. 
282 As stated above, the ISApl1 is part of the IS30 family. The family has been shown to 283 mobilize through a copy (out) and paste mechanism, forming circular intermediates of a 284 single IS during transposition. The family is further known to have a high affinity for certain target sites resembling their IR sequence ${ }^{46-48}$. Multiple studies have investigated the mechanisms of ISApll in mobilising the mcr-1 gene and found that during each transposition event, the transposon was a circular intermediate covalently closed doubled stranded DNA, $5699 \mathrm{bp}$ in size and generated a 2 bp direct repeats at the insertion site which was an AT-rich region $37,44,47,49$, a similar mechanism seen in the IS30 family. ISApl1 is most likely an important factor responsible for the insertion and fixation of the $m c r-1$ gene into various classes of self-transmissible plasmids and host chromosomes ${ }^{37,41,50}$. The formation of an intermediate structure consisting of ISApll and mcr-1 during mobilization indicates that the resistance genes have become highly mobilizable in both plasmids and the chromosomes ${ }^{41}$. After the first identification of $m c r-1$ in pHNSHP45 ${ }^{11}$, an Incl $_{2}$ plasmid, $m c r-1$ was thereafter detected in a wide range of conjugative plasmids, $\mathrm{IncI}_{2}, \mathrm{IncHI}_{2}, \mathrm{IncX}_{4}, \mathrm{IncF}$, and IncP with the potential to mediate the dissemination of $m c r-1$ genes into other Gram-negative bacteria 50. Petrillo et al. (2016) suggest that the insertion of the complete transposon triggers the rapid mobilization of conjugative plasmids, encouraging their dissemination across the Enterobacteriaceae family ${ }^{51}$. The copy out and paste in mechanisms allow for the transposition of the $m c r-1$ cassette, and the decay properties of ISApll further transfix the resistance gene into a plasmid or chromosome ${ }^{49,52}$.

302

Snesrud et al. (2017) and Li et al. (2019) discovered that ISApll is highly active and that a single copy of ISApll can mobilize independently of $m c r-1$ across the host genome in AT regions with a slight central GC bias ${ }^{49,53}$. A sequencing analysis of four $m c r-1$ containing isolates performed by Snesrud et al. (2017) identified two to six copies of ISApll element throughout the isolates' genome. The highly active nature of the ISApll elements thereafter triggers the deletion of the flanking ISApll copies to prevent further plasmid rearrangements 40, 49 . Snesrud et al. (2016) analysis of the $m c r-1$ sequence environment showed that Tn6330 has a strong tendency to decay through deletion, removing parts of, or both copies of ISApll, thus transfixing mcr-1 into a vector plasmid. This has led to the observation of many sequences lacking one or both of ISApl1 ${ }^{37,44}$. Composite transposons in the IS30 family have been shown to contribute to replicon stabilization through transposition and illegitimate recombination 44,47 . The loss of ISApll elements results in the loss of transposability, stabilizing the $m c r-1$ cassette in plasmids, which facilitates the widespread dissemination of 
315 the colistin resistance gene in self-transmissible plasmids ${ }^{44,54,55}$. As discussed, ISApll has a

316 significant bias for insertion in AT-regions and generates TSD of two or three bases. The 317 analysis of the $m c r-1$ cassette in the absence of ISApll elements has shown that the cassette is 318 found in similar locations as per plasmid type and flanked by conserved trinucleotides (5'319 ATA-3') that are found immediately downstream of the ISApll IRR ${ }^{44,56}$. This is because the 320 deletion event involves 1-4 flanking nucleotides that remain at the deletion junction ${ }^{40}$.

321 An analysis of $m c r-1$ sequences deposited in the public database has shown four general 322 structures of $m c r-1$ sequences: the complete composite transposon with both copies of ISApll 323 elements; structures with a single copy of ISApll located downstream of mcr-1; structures 324 that lost both copies and a rare fourth structure with a single copy of ISApll located upstream 40, 44 . In structures with a single copy of ISApl1 found upstream and the IRR sequence of the downstream of deleted ISApl1, Snesrud et al. (2016) suggest that the transposase encoded by the upstream ISApll can recognize the downstream IRR and thereafter still be able to mobilize the bracketed region without a complete composite transposon ${ }^{44}$. The partially or complete removal of ISApll was through an illegitimate recombination that generated mismatches and deletions. Sun et al. (2018) found that the 3' end of the mor cassette unit was flexible in all IncX 4 plasmids and the sequence could match with the perfect IRR of ISApll, though all IncX $\mathrm{X}_{4}$ currently lack ISApll elements. The evidence from this study suggests that the TSD generated, and the six mismatches acquired through illegitimate recombination could be identified as a "relic" to track an insertion event that resulted in the subsequent loss of ISApl1 ${ }^{32}$. The loss of ISApll elements in $\mathrm{IncX}_{4}$ was conducive to maintaining the $m c r-1$ cassette on the plasmid ${ }^{32}$, increasing its stability, and thus allowing for the dissemination of resistance genes via the plasmids ${ }^{44,54,55}$. The identification of these IRR in IncX $\mathrm{X}_{4}$ plasmids allows for the conclusion that ISApll was associated with the transposition of the $m c r-1$ cassette into $\mathrm{IncX}_{4}$ plasmids ${ }^{57}$.

341 The acquisition of $m c r-1$ bearing plasmids has been shown to have a beneficial effect on the 342 host, improving bacterial survival in the presence of colistin treatment ${ }^{58}$. The acquisition and expression of the mcr-1 gene results in the incorporation of MCR-1 into the bacterial membrane and the phosphoethanolamine (PEtN) modification of the lipopolysaccharides (LPS) ${ }^{59}$. However, multiple studies have shown that the expression of $m c r-1$ imposes a 346 fitness cost by placing an energy burden on the host ${ }^{60}$, impairing cell growth, and 347 diminishing bacterial fitness ${ }^{59}$. Andersson et al. (2006) ${ }^{61}$ explained that a significant fitness 
cost is seen when the susceptible strain outcompetes the resistant strain in an antibiotic free environment. The imposed fitness cost of a conjugative plasmid harbouring a resistance gene has been shown to be because of various factors such as the resistance mechanisms, the bacterial species, and the antibiotic ${ }^{58}$.

Evaluating the cost of colistin resistance on resistant strains, it is shown that certain chromosomal mutations within genes such as $\operatorname{mgr} B$ have no significant fitness cost on $K$. pneumoniae ${ }^{62}$ whilst genes such as $p m r B$, do ${ }^{63}$. Giordano et al. (2019) ${ }^{63}$ found that the expression of the mcr- 1 gene imposes less of a burden on $K$. pneumoniae than the mutated $p m r B$ gene. The chromosomal mutations within $\operatorname{pmr} A B$, $c r a b$, $p h o P Q$, and $m g r B$ genes have been shown to mediate colistin resistance through the phosphorylation of lipid A ${ }^{64-66}$. Tietgen et al. (2018) discovered that the fitness costs imposed by $m c r-1$ plasmid carriage, such as growth rates and cytotoxicity, could be species-specific ${ }^{67}$. Particularly, the acquisition of an $m c r$ - 1 -harbouring plasmid in $K$. pneumoniae has been shown to impose a significant fitness cost on the host ${ }^{58}$, but multiple studies have shown that the acquisition of an $\mathrm{IncI}_{2}$ plasmid, in various sizes, carrying $m c r-1$ had no significant cost on the host ${ }^{68,69}$. This may be plasmid and/or species specific or may be due to acquired compensatory mutations within the IncI $_{2}$ plasmid. However, the overexpression of $m c r-1$ was seen to result in profound changes in the architecture of the outer membrane, resulting in the loss of membrane structural integrity and causing leakage of cellular cytoplasm, resulting in cell death ${ }^{59,70}$.

Yang et al. (2017a) ${ }^{59,70}$ found that the overexpression of $m c r-1$ imposes a significant cost by decreasing the growth rate, causing significant membrane degradation and moderate fitness loss. They came to this conclusion through evaluating the effects of $m c r-1$ expression on the relative fitness of $E$. coli TOP10 and found that with increasing levels of $m c r-1$ expression resulted in a significant fitness burden on the host ${ }^{59,70}$. An analysis of the cellular morphology in the $m c r-1$ overexpressed strains using a transmission electron microscopy showed cell architecture alterations and a complete loss of cellular morphology. The overexpression of $m c r-1$ altered the structural integrity of the outer membrane and further impaired the cell membrane ${ }^{59}$. They finally found that the embedding of $M C R-1$ into the outer membrane and the PEtN modifications of Lipid A were the leading factors contributing to fitness cost and membrane degradation. Therefore, the expression of $m c r-1$ in host strains is tightly controlled to regulate the $m c r-1$ fitness $\operatorname{cost}^{70}$. 
Mcr- 1 expression is therefore quite toxic for the bacterial host, and the acquisition of a $m c r-1$ bearing plasmid thereafter results in compensatory adaptation that allows for the maintenance of high-cost conjugative plasmids ${ }^{19,71,72}$. Dahlberg et al. (2003) ${ }^{72}$ found that the cost of plasmid carriage is reduced over long-term culture because of compensatory mutations. The host chromosome or plasmid evolves compensatory mutations that, in the case of plasmids, enhance the fitness of the host, and in the case of chromosomal mutations, aid the host in evolving towards new growth conditions by decreasing the plasmid carriage cost ${ }^{72}$. This has been seen in multiple studies where $m c r-1$ bearing plasmids initially imposed a biological cost on the transformant. However, overtime, the cost of plasmid carriage in long-term cultures was largely compensated for and plasmids were stably maintained through passages $59,63,67,71,73$

Ma et al. (2018a) ${ }^{71}$ investigated the potential mechanisms involved in compensatory adaptation through comparative genomics and identified single nucleotide polymorphisms in several genes. Amongst the genes identified in this study are $d n a K$, which encodes a molecular chaperon involved in chromosomal DNA replication, and $c p o B$, which encodes an RHS repeat protein involved in maintaining the cell envelope integrity during cellular division ${ }^{71}$. These two genes are located on the chromosome and have non-synonymous single nucleotide polymorphisms (SNPs). The role of these genes in reducing plasmid carriage cost is unknown and may represent novel mechanisms. The study further shows that bacteria may use different strategies to reduce the fitness cost of plasmid carriage under different environmental conditions ${ }^{71}$

In the absence of antibiotics (colistin) selective pressure, mcr- 1 bearing plasmids have been shown to be less maintained and that the complete elimination of the $m c r-1$ gene within a population is possible ${ }^{58}$. Nang et al. (2018) ${ }^{58}$ performed a plasmid stability assay and found that in the absence of colistin, there was a gradual loss of the $m c r-1$ plasmid, there was a decrease in its maintenance within the population. This may be due to the instability of $m c r-1$ harbouring plasmids ${ }^{58}$. Arcilla et al. (2016) have shown the complete elimination of $\mathrm{mcr}-1$ bearing bacteria in travellers returning to their home country after a month ${ }^{74}$.

\section{MCR-1 structure}

$M C R-1$ is a 541 amino acid, integral membrane protein made up of two domains: a Cterminal periplasmic catalytic domain and an N-terminal 5' -helix transmembrane domain ${ }^{75}$, 76. The transmembrane (TM) domain is made up of 5-membrane spanning $\alpha$-helixes with an 
412 overall positive charge because of positively charged residues, which interact with the 413 negatively charged phospholipid head groups of the membrane bilayer. The TM domain 414 anchors the protein into the inner membrane and is connected to the catalytic domain through 415 a bridging helix ${ }^{75}$. The catalytic domain is made up of both positively and negatively charged 416 residues, where the negatively charged residues create the binding pockets and allow them to 417 be buried within the domain ${ }^{75}$.

418 The overall shape of MCR-1 is a hemispherical shape composed of several $\beta-\alpha-\beta-\alpha$ motifs made up of $\beta$-strands sandwiched between $\alpha$-helical structures ${ }^{12,77}$. The catalytic domain has an alkaline phosphatase family $\alpha / \beta / \alpha$ fold, also with a hemispheric shape equipped with a zinc binding pocket containing a conserved phosphothreonine-285 residue (Figure 6) ${ }^{12,77}$.

422 The pocket is common to PEtN transferases and alkaline phosphatase; each enzyme, however, differs in the orientation and number of zinc molecules ${ }^{77}$. The pocket is proposed to be critical for the nucleophilic attack of the phosphate of the donor PE substrate by stabilizing the alkoxide of the Thr $285^{77}$. The Thr285 residue, is the catalytic nucleophile that acts as both a nucleophile and a PEtN acceptor during the catalytic mechanisms. The residue is critical to MCR-1's function as mutations to this residue significantly decrease MCR-1's activity ${ }^{77,78}$. The catalytic domain of MCR-1 is further made up of six cysteine residues that form three disulphide bonds, Cys281/Cys291, Cys356/Cys364 and Cys414/Cys422 ${ }^{77}$ that stabilize and anchor the $\beta-\alpha-\beta-\alpha$ motifs ${ }^{12}$. These disulphide bonds are conserved, and equivalents are present in both LptA and EptC transferases ${ }^{77}$, although LptA has four more cysteine residues.

433 The zinc binding pocket is in the active site of MCR-1 and is made up of conserved residues viz., Asp465, Glu246, His466, His395, and Thr285, and is made up of zinc molecules (Figure $6 b)^{77,79}$. The conserved residues are critical for the substrate binding of MCR-1 ${ }^{79}$ and mutations in these amino acids abolish the MCR-1 activity, lowering the colistin MIC value down to control levels ${ }^{13}$. The five conserved residues are well conserved in MCR-1, LptA, EptC and other alkaline phosphatase family members, although the nucleophile residue may differ between enzymes ${ }^{78}$. MCR-1 has three zinc molecules clustered around the active site: $\mathrm{Zn} 1$ is buried within the active site and co-ordinated by the phosphate oxygen of Thr285; it is conserved in LptA and EptC ${ }^{77}$. Zn2 is co-ordinated by His395, bound to a phosphate oxygen of Thr285 and three water molecules, forming a trigonal bipyramidal configuration seen in

443 Figure $6 b^{77}$. Hu et al. (2016a) found that $\mathrm{Zn} 2$ is not critical for maintaining MCR-1 activity. 
444 This may be because it is located on the surface of the active site. A structural comparison 445 between LptA, EptC and MCR-1 found that the Zn2 site is less conserved. Hence, Hinchliffe 446 et al. (2017) ${ }^{78}$ concluded that an intact $\mathrm{Zn} 2$ site was not a prerequisite for MCR-1's catalytic 447 activity. However, His395 residue is important for the structure and activity of MCR-1. The $448 \mathrm{Zn3}$ molecule, unlike the other zinc molecules, is not co-ordinated by the conserved residues 449 but is tetrahedrally co-ordinated by four water molecules. The seven water molecules found 450 in the active site, co-ordinating $\mathrm{Zn} 2$ and $\mathrm{Zn} 3$, are embedded in the protein through hydrogen 451 bonding ${ }^{77}$. The catalytic domain is thus a zinc-rich area (Fig. 6b), suggesting that MCR-1 452 may be able to attract zinc ions at different levels into the domain ${ }^{13}$. The role of zinc in 453 mediating lipid A modification, the catalytic mechanism, was evaluated by measuring the 454 colistin MIC in the presence and absence of EDTA. Hinchliffe et al. (2017) ${ }^{78}$ found clear 455 reductions in colistin MIC values after EDTA treatment and concluded that the presence of 456 zinc in the active site was important for MCR-1 function.

MCR-1 mediates the transfer of PEtN from the primary phosphatidylethanolamine (PE) to lipid A moiety at the $4^{\prime}$-phosphate group ${ }^{13,79}$. Wei et al. (2018) ${ }^{75}$ and Liu et al. (2018) ${ }^{76}$ investigated the molecular mechanism involved in this process. Wei et al. (2018) identified that the active site within the catalytic domain is made up of two binding pockets: the PEtN binding pocket and the Lipid A binding pocket. These binding pockets are in close proximity and are integrated within each other ${ }^{75}$. Wei et al. (2018) ${ }^{75}$ observed that ethanolamine was a good analogue of PEtN and D-glucose for lipid A. Ethanolamine (ETA) is a good analogue as it mimics the covalent PEtN-enzyme intermediate. Lipid A is made up of two glucosamine units that are attached to acyl chains. Thus, monosaccharides and disaccharides can mimic a Lipid A molecule as they are both hexacyclic compounds ${ }^{75,76}$.

The PEtN binding pocket that accommodates ETA is made up of Glu246, Thr285, Asn329, Lys333, His395, Asp465, His466 and His478 residues ${ }^{75}$. This pocket is responsible for the binding of phosphatidyl-ethanolamine (PE), which is stabilized through hydrogen bonding with Asn329, a water molecule, and phosphorylated Thr285 ${ }^{75}$. Analysis of the entry of ETA into the pocket showed that the pocket undergoes conformational changes to adjust to the substrate. These included a $50^{\circ}$ rotation of the His 395 , accomplished by breaking a hydrogen bond with a water molecule (wat7) and creating a new hydrogen bond with a new water molecule (wat8) ${ }^{75}$. This releases the wat7 molecule from the PEtN binding pocket and thus, collectively, the conformational changes create room to accommodate the substrate, ETA. 
477 molecule and a nucleophilic state at $\mathrm{Thr} 285^{75}$. The $\mathrm{Zn} 1$ molecule subsequently facilitates the

478 stabilization of the nucleophilic state of Thr285 that allows that residue to thereafter attack

479 the PEtN, creating a PEtN enzyme intermediate. This constitutes the first step of the MCR-1480 mediated catalytic process ${ }^{75}$.

481 Wei et al. (2018) ${ }^{75}$ and Liu et al. (2018) ${ }^{76}$ investigated the mechanisms behind PEtN-

482 transfer reaction with a lipid A analogue, D-glucose, identified within the Lipid A binding

483 pocket. This pocket is made up of the following residues: Thr283, Ser284, Tyr287, Pro481

484 and Asn482, that is located near the Thr285 residue (Figure 7). The analysis of D-glucose

485 found that D-glucose was held in the pocket by Thr285, Ser284 and Asn482 and was flanked 486 by Tyr281 and Pro481 forming a sandwich structure of a $\pi$ - $\pi$ conjugative interaction ${ }^{75,76}$. The

487 importance of the residues in both PEtN and Lipid A binding pockets in MCR-1 activity were

488 evaluated through mutation construction. Mutations within Thr285, Asn329, Lys333, Glu246,

489 His398, Asp465, His466 and His478 of the PEtN binding pocket and Tyr281 and Pro481 of

490 the Lipid A binding pocket, resulted in a decrease in colistin MIC values ${ }^{75}$. However, these

491 mutations did not disrupt the protein expression and membrane localization of the MCR-1

492 protein. The mutations of Tyr281 and Pro481 in the lipid A binding pocket highlights the

493 importance of this pocket in the MCR-1 activity. Wei et al. (2018) ${ }^{75}$ suggests that it could

494 bind to the glucosamine group of Lipid A and allows for the transfer of the reactive

495 phosphate group from PEtN enzyme intermediate to lipid A. Thus, the second step of the

496 catalytic process therefore involves the transfer of PEtN to Lipid A that is situated in a nearby

497 pocket $^{75}$.

498 The MCR-1 catalytic domain is therefore made up of a PEtN binding pocket and a Lipid A 499 binding pocket that mediate the transfer of PEtN from the PEtN binding pocket to lipid A 500 moiety at the 4'-phosphate group ${ }^{13,79}$. This activity is validated through MALDI-TOF mass 501 spectrometry (MS), provides in-vivo evidence of the MCR-1 activity ${ }^{79,80}$. This is 502 accomplished by evaluating the LPS lipid A MS profile in the presence and absence of $m c r-1$ 503 expression as adding PEtN increases Lipid A mass units $(+123)^{79,81,82}$. In the absence of $504 m c r-1$ expression, there is a single Lipid A peak $(m / z=1797.4)$ and in the presence of $m c r-1$ 505 expression, there are two unique peaks. The first peak is the wildtype bis-phosphorylated, hexa-acylated lipid A $(m / z=1797.4)$ and the second peak is the PPEtN-4' $(\mathrm{m} / z=1920.5)^{81}$.

MCR-1 has thus proven to have PEtN transferase activity and has a sequence and structural 508 similarity to EptC and LptA PEtN transferases in Campylobacter jejuni ${ }^{14}$ and Neisseria 509 meningitidis ${ }^{83}$, respectively ${ }^{77-79}$. The active sites of the three PEtN transferases are highly 
medRxiv preprint doi: https://doi.org/10.1101/2022.02.28.22271560; this version posted March 1, 2022. The copyright holder for this preprint (which was not certified by peer review) is the author/funder, who has granted medRxiv a license to display the preprint in perpetuity.

It is made available under a CC-BY-NC-ND 4.0 International license .

510 conserved, i.e., the phosphorylated catalytic nucleophile Thr285, disulphide bonds, zinc

511 binding pockets and the conserved active site residues ${ }^{78}$. Therefore, these three sites are

512 important for MCR-1 function; these conserved mechanistic activities and binding pockets

513 will allow for the use of MCR-1 inhibitors to also inhibit chromosomally encoded PEtN

514 transferases, restoring colistin susceptibility in acquired and intrinsically resistant bacteria ${ }^{77}$.

\section{Mcr-2 variant}

$516 M c r-2$ was first identified in ten E. coli isolates during a passive surveillance screening of 517 diarrhoea in calves and piglets, and like $m c r-1$, mcr-2 was located on a conjugative plasmid $518\left(\mathrm{IncX}_{4}\right)$ and was able to confer clinical colistin resistance $(4-8 \mathrm{mg} / \mathrm{L})^{20}$. The gene was 519 identified due to the presence of a putative membrane protein identified as a PEtN transferase 520 in $m c r-1$ negative isolates ${ }^{20}$. This variant has a $76.75 \%$ and $80.65 \%$ nucleotide sequence and amino acid identity, respectively, to $m c r-1^{20}$. $m c r$ - 2 encodes a 538 amino acid polypeptide consisting of two domains: a C-terminal periplasmic catalytic domain and an N-terminal 5'helix transmembrane domain ${ }^{20,33}$. Sun et al. (2017b) found that the acquisition of the transmembrane domain allows for the correct localization of PEtN transferases within the periplasm and that the deletion of this domain impairs MCR-2's ability to confer colistin resistance.

A genetic analysis of the $\mathrm{IncX}_{4}$ plasmid found that $m c r-2$ was located within two IS1595-like ISs and a 279 bp open reading frame (ORF), located downstream the $m c r-2$ gene ${ }^{20}$. The ORF encodes a PAP2 membrane-associated lipid phosphatase which is related to the PAP2 protein encoded by the ORF of $m c r-1^{20,84}$. The ORF of $m c r-2$ has a $41 \%$ identity to the phosphatidic acid phosphatase encoded by M. osloensis. When Xavier et al. (2016) removed the $m c r-2-$ pap2 from the IS1595 backbone, a BLASTn search produced a single hit to M. bovoculi strain with a $75 \%$ identity across a $100 \%$ query coverage. To support the hypothesis that the mcr-2 cassette originated from Moraxella sp., a phylogenetic analysis of the MCR-2 protein was performed and found that the protein was a distinct protein from $M C R-1$ and might have evolved from M. catarrhalis $^{20}$. Sun et al. (2017b) suggests that the emergence of the PEtN transferases, MCR-1, MCR-2 and Neisseria LptA was a parallel evolutionary event for

538 functional acquisition of colistin resistance during some environmental selection pressure, 539 i.e., the intensive use of colistin in animal feed ${ }^{33}$.

540 IS1595 is composed of a transposase gene flanked by two inverted repeats (18 bp each). Mcr-

5412 is thus present within a complete transposon which allows for horizontal gene transfer ${ }^{33}$. 
medRxiv preprint doi: https://doi.org/10.1101/2022.02.28.22271560; this version posted March 1, 2022. The copyright holder for this preprint (which was not certified by peer review) is the author/funder, who has granted medRxiv a license to display the preprint in perpetuity.

It is made available under a CC-BY-NC-ND 4.0 International license .

542 Sun et al. (2017b) found that the IS1595 composite transposon was able to form circularized 543 intermediates, which were identified during an inverse PCR assay. Hence, the IS1595 544 elements are involved in the mobilisation of the $m c r-2$ cassette via homologous 545 recombination events, which like $m c r-1$, allows for the dissemination of the resistance gene 546 across diversified bacterial hosts ${ }^{33}$.

547 After the first identification of $m c r-2$ in Belgium on an IncX $\mathrm{X}_{4}$ plasmid, an effective vehicle

548 for dissemination of resistance and virulence genes with a high transfer frequency ${ }^{20,33}$, it was 549 thereafter identified in Salmonella sp. on IncX 4 plasmids in Belgium in 2018 from retail meat 550 collected in $2012^{85}$. It has subsequently been found in pig and poultry samples in 19 551 provinces in China, where the prevalence of $\mathrm{mcr}-2$ in the study was $56.3 \%$ in poultry ${ }^{86} . \mathrm{Mcr}$ 5522 was then found in clinical settings in Iran, in stool samples collected between 2011-2016 ${ }^{87}$. 553 In Egypt, $m c r-2$ was widespread and identified in humans, wild birds, and the environment 554 (water sources) ${ }^{88}$. Compared to $m c r-1$, mcr-2 has not spread across the world and imposed a 555 big threat to public health though found on a low fitness burden plasmid. The gene has 556 however spread well within the Enterobacteriaceae family i.e., E. coli, K. oxytoca, $K$. 557 pneumoniae and Salmonella sp.

558 The mor-2.2 variant: $m c r-6$

559 AbuOun et al. (2017) ${ }^{42}$ identified an mcr-2.2 variant in Moraxella pluranimalium strain 560 isolated from a pig in Great Britain. The MCR-2.2 protein was found to have an $87.9 \%$ amino 561 acid identity to MCR-2, encoding 65 amino acid substitutions ${ }^{42}$. Partridge et al. (2018) ${ }^{89}$ 562 suggested that since $m c r-2.2$ encodes a protein that is $87.9 \%$ identical to the original MCR-2, 563 it should be labelled as $m c r-6$. The $m c r-6$ gene like $m c r-1$ and $m c r-2$ was associated with the 564 PAP2 gene located downstream of $m c r-6^{42}$. The $m c r-6$ has only been identified in the $M$. 565 pluranimalium MSG47-C17 strain isolated in 2012 and has not disseminated into the 566 Enterobacteriaceae family. AbuOun et al. (2017) ${ }^{42}$ however highlights that Moraxella 567 species could have been the source of mcr-pap2 genes.

568 Mcr-3 variant

569 The first identification of $m c r-3$ was in $E$. coli isolated from pigs in China ${ }^{90}$. The identified 5701626 bp putative PEtN transferase has a $45.0 \%$ and $47.0 \%$ nucleotide sequence identity to $571 m c r-1$ and $m c r-2$ and an amino acid sequence identity of $32.5 \%$ and $31.7 \%$, respectively ${ }^{90}$. 572 Using RaptorX, Yin et al. (2017) ${ }^{90}$ predicted that MCR-3 protein, like MCR-1, and MCR-2, 573 is made up of two Domains, domain 1 containing a five-transmembrane helix and domain 2 
574 containing the periplasmic domain made up of the putative catalytic centre ${ }^{90}$. Despite the

575 difference between $m c r-3$ and the other $m c r$ genes, Kieffer et al. (2018) ${ }^{91}$ found that an $m c r$ -

5763.12 variant had the same PEtN transferase activity and the expression of $m c r-3$ resulted in an

577 8-fold increase in MIC value of colistin ${ }^{92}$. An LPS analysis showed that both MCR-1 and

578 MCR-3 produced an identical additional peak at $m / z 1921$ in $m c r-1$ and $m c r-3$ positive E.

579 coli. Thus, the differences in nucleotide or amino acid sequences between the two mcr genes

580 had no impact on the PEtN activity ${ }^{91,93}$ and proving that MCR-3 confers colistin resistance in

581 the same manner as MCR-1 and MCR-2 ${ }^{91}$.

582 To further elaborate this observation, the expression of $m c r-3$ has been shown to significantly

583 impair the cell wall integrity and decrease the electron density of $m c r-3$ producing E. coli ${ }^{94}$, a 584 characteristic that has been previously described in $m c r-1$ producing isolates ${ }^{67,70,94}$. Yang et 585 al. (2020) ${ }^{94}$ further evaluated the fitness cost imposed by $m c r-3$ expression and compared it 586 to that of $m c r-1$ and found that the expression of both $m c r$ genes had an impact on the 587 bacterial fitness; however, the $m c r-3.1$ and $m c r-3.5$ imposed lesser fitness costs.

Mcr-3 genetic context is made up of a diacylglycerol kinase $(d g k A)$ gene located downstream the $m c r-3$ gene and is thereafter flanked by a truncated $(\Delta)$ ISKpn40 upstream and an intact ISKpn40 downstream ${ }^{52}$. In some cases, a $\Delta \operatorname{TnAs} 2$ element is located upstream of the $\Delta \mathrm{ISKpn} 40$ element ${ }^{52,90,95}$, and the genetic context ( $\triangle \mathrm{TnAs} 2-\Delta \mathrm{ISKpn40-mcr-3-dgkA-}$ ISKpn40) is flanked by an IS26 element upstream and an intact IS15DI element downstream $^{96}$ 34, 52. These elements, ISKpn40, TnAs2, IS26 and IS15DI were identified and hypothesised to play a role in the transposition of the $m c r-3$ cassette among different species or bacterial genera ${ }^{35,52,97}$. Sia et al. (2020) ${ }^{52}$ identified two circular intermediates of $3535 \mathrm{bp}$ and 5990 bp made up of $m c r-3-d g k A$-ISKpn40 and IS $\triangle 26-T n A s 2-\Delta I S K p n 40-m c r-3-d g k A$ ISKpn40, respectively, during conjugation experiments. Wang et al. (2018) ${ }^{35}$ evaluated the transferability of the $5990 \mathrm{bp}$ circular intermediate and concluded that the $\Delta$ IS26 and intact IS15DI mobilises the mcr-3.1 via homologous recombination through the formation of circular intermediates. The IS-mediated transposition enables the mobilisation of the $m c r-3$ resistance gene between the chromosome and plasmids, which further contributes to the dissemination of resistance genes ${ }^{34,35}$. Similar conclusion was reached with the 3535 bp circular intermediates in a study performed by Xiang et al. (2018), ${ }^{97}$ which showed that mobilisation of the $m c r-3$ core segment ( $m c r-3-d g k A)$ through ISKpn40 elements facilitated 605 its spread into various plasmids. 
medRxiv preprint doi: https://doi.org/10.1101/2022.02.28.22271560; this version posted March 1, 2022. The copyright holder for this preprint (which was not certified by peer review) is the author/funder, who has granted medRxiv a license to display the preprint in perpetuity.

It is made available under a CC-BY-NC-ND 4.0 International license .

606 The $m c r-3.12$ variant has a 99\% nucleotide sequence identity with an Aeromonas veronii 607 sequence ${ }^{91}$ and significant (77\%) amino acid sequence identity to three PEtN transferases 608 found within the genera 90, 91, 98. It is suggested that $m c r-3$ genes originated from the 609 Aeromonas genus, or the $m c r-3$ gene is widely disseminated as an acquired resistance trait 610 and thus also found in Aeromonads ${ }^{91}$. It is however thought that $m c r-3$ was initially 611 transposed from the Aeromonas genera to the Enterobacteriaceae family through ISKpn40612 mediated transposition. The ISKpn40 elements encode two ORF and the second ORF has a $61399 \%$ identity to both a transposase from Aeromonas sp. and an integrase from Aeromonas 614 caviae $^{99}$. This IS element is found flanking the mcr-3 segment and was also shown to 615 mobilise through homologous recombination ${ }^{52,97}$. The last evidence of $m c r-3$ originating 616 from Aeromonas includes the presence of TnAs 2 located upstream of the $m c r-3$ gene ${ }^{90}$. The 617 transposon has only been identified in A. salmonicida and because its sequence in pWJ1 618 (original $m c r-3$ plasmid) is a partial sequence, it is unlikely to have mobilised the $m c r-3$ gene 61990,95 . This evidence supports the possibility of the Aeromonas genus being a possible 620 progenitor of $m c r-3$ genes ${ }^{90}$.

621 Mcr-3 and its variants are disseminated within Enterobacteriaceae, having been identified in 622 E. coli, Salmonella sp. and K. pneumoniae in healthcare centres, aquaculture, wastewater, and 623 in animals $18,34,90,92,95,98,100$. The resistance genes have been identified in both transmissible 624 and non-transmissible plasmids such as IncA/C $2, \operatorname{IncHI}_{2}, \operatorname{IncHI}_{2 \mathrm{~A}}, \mathrm{IncF}_{\mathrm{II}} / \mathrm{F}_{\mathrm{IB}}, \mathrm{IncY}$, IncR, 625 IncF, and IncP and in many variant mutations. The first identified $m c r-3$ gene was identified 626 on an $\mathrm{IncHI}_{2}$ plasmid replicon (pWJ1) in E. coli isolated from pigs in China ${ }^{90}$. Thereafter, 627 multiple $m c r-3$ variants have been identified with one or more amino acid substitutions. Yang 628 et al. (2020) evaluated the impact of $m c r-3$ expression on bacterial fitness using two $m c r-3$ 629 variants, $m c r-3.1$ and $m c r-3.5$ (T488I, M23V, A456E) ${ }^{94}$. The study showed that although the 630 expression of both variants imposed a fitness cost and impaired the cell wall integrity, the 631 expression of $m c r-3.5$ was less costly ${ }^{94}$. Yang et al. (2020) ${ }^{94}$ showed that the amino acid 632 substitutions $\mathrm{A} 457 \mathrm{~V}$ and T448I, seen in mcr-3.5, had strong compensatory effects when 633 introduced in $m c r-3.1$. The introduction of these substitutions, individually, resulted in an 634 increased fitness of up to $45 \%$. However, double substitutions demonstrated a negative 635 epistasis.

636 This study highlights an interesting concept about all $\mathrm{mcr}$ genes i.e., the $\mathrm{mcr}$ variants may 637 encode compensatory mutations that mitigate the expression of $m c r$ genes and thus, is an 638 evolutionary mechanism for the worldwide dissemination of $m c r$ genes ${ }^{94}$. Though variants 
medRxiv preprint doi: https://doi.org/10.1101/2022.02.28.22271560; this version posted March 1, 2022. The copyright holder for this preprint (which was not certified by peer review) is the author/funder, who has granted medRxiv a license to display the preprint in perpetuity.

It is made available under a CC-BY-NC-ND 4.0 International license .

639

640

641

642

643

644

645

646

647

648

649

650

651

652

653

654

655

656

657

658

659

660

661

662

663

664

665

666

667

668

669

such as $m c r-3.10$ has seven substitutions (V122G, R297L, E337K, H341Y, D358E, Q468K and $\mathrm{I} 313 \mathrm{~V}){ }^{92}$ in both the putative transmembrane region and catalytic domains, these substitutions do not affect MCR-3.10's ability to confer colistin resistance. Wang et al. (2018d) showed that similar to the original $m c r-3$, the expression of $m c r-3.10$, results in an 8fold increase in colistin MICs. Similar results were seen with $m c r-3.5^{95}$.

\section{Mcr-4 variant}

Mcr-4 was first identified in $S$. Typhimurium isolated from the caecal content of a pig at slaughter in Italy in $2013{ }^{101}$. The $S$. Typhimurium was colistin-resistant and negative for known $m c r$ genes. MCR-4 respectively has an amino acid sequence identity of $34 \%, 35 \%$ and 49\% to MCR-1, MCR-2, and MCR-3, and like other PEtN transferases, can mediate colistin resistance through Lipid A modification ${ }^{101}$. MCR-4, however, has an 82\%-99\% amino acid sequence identity to one large PEtN transferase found in Shewanella sp., and the mcr-4.3 variant has a $100 \%$ nucleotide sequence identity to a chromosomal PEtN transferase encoded by $S$. frigidimarina ${ }^{98,101,102}$. Mcr-3 and $m c r-4$ are suggested to have originated from aquatic environments, as Aeromonas and Shewanella sp. are aquaculture fish pathogens that are intrinsically resistant to colistin ${ }^{98}$. The dissemination of these $\mathrm{mcr}$ genes to the Enterobacteriaceae family may have been carried through plasmids from the host genome. The mechanism underlining this mobilisation is yet to be discovered ${ }^{98}$.

Mcr-4 was initially identified on an 8749 bp ColE10 plasmid, which encoded a RepB replicase, mobA/L mobilisation proteins, a RelE toxin and excll gene ${ }^{101,103}$. In other cases, the ColE plasmid was found to encode a RepA replicase instead of RepB. However, both plasmids showed a 99\% nucleotide sequence identity to plasmids from Pantoea species, with a $65 \%$ coverage ${ }^{101-103}$. The $m c r-4$ gene was flanked by IS5 elements on some plasmids and on other plasmids, it was flanked by an $\Delta \mathrm{IS} 10$ element upstream and an IS1294 element downstream ${ }^{103}$. Genetic analysis found that the ColE plasmid encodes a conserved 59-bp region upstream the $m c r-4$ gene, and this region is predicted to encode the -35 (TTATTT) and -10 (AGCTAGTAT) promoter regions. ${ }^{102}$ This allows for ColE plasmids to replicate independently in different bacterial species and genera ${ }^{101}$. ColE plasmids are broad-range non-conjugative plasmids whose mobilisation, however, require a helper plasmid; nevertheless, the mobilisation of the $m c r-4$ gene is hypothesized to be achieved through a transposition event mediated by the IS5 element ${ }^{101}$. 
medRxiv preprint doi: https://doi.org/10.1101/2022.02.28.22271560; this version posted March 1, 2022. The copyright holder for this preprint (which was not certified by peer review) is the author/funder, who has granted medRxiv a license to display the preprint in perpetuity.

It is made available under a CC-BY-NC-ND 4.0 International license .

670 A genomic analysis of the initial $m c r-4$-producing $S$. Typhimurium genome found the 671 ColE10 replicon located within the host chromosome integrated within the Type 1 672 methylation gene. Carattoll et al. (2017) suggest a transposition event mediated the 673 chromosomal integration of the ColE10 plasmid ${ }^{101}$. Mcr-4 has been isolated from both 674 humans and animals in Spain, Belgium, Italy, and China in Enterobacteriaceae ${ }^{101,104-106}$. An 675 inactive $m c r-4.3$ variant identified by Teo et al. ${ }^{105}$ (2018) was found to encode two missense 676 mutations, V179G and V236F, that inactivated the PEtN transferase activity ${ }^{102,105}$. A 677 comparative alignment of the MCR-4.3 to MCR-1 and MCR-2 found that the active residues 678 were conserved in MCR-4.3 ${ }^{105}$. However, an MS spectrum of lipid A in $m c r-4.3$-expressing 679 isolates showed $m c r-4.3$ failed to modify lipid A ${ }^{102}$. The transformation of $E$. coli with an 680 mcr-4.3 expressing vector resulted in no difference in colistin MIC values, suggesting that $m c r-4.3$ does not confer colistin resistance ${ }^{102,105}$. Thus, some compensatory mutations in $m c r$ may aid in fitness cost while others such as those seen in $m c r-4.3$ significantly altered the PEtN transferase activity of $m c r-4.3^{102}$.

684

685

686

687

688

689

690

691

692

693

694

695

696

697

698

699

700

701

702

Mcr-5 variant

Mcr-5 was first identified in a d-tartrate-fermenting S. Paratyphi B isolated from foodproducing animals across Germany between 2011 and 2013. Following this discovery of $\mathrm{mcr}$ 5 , further screening resulted in the identification of fourteen additional mcr-5-producing isolates. These were isolated between 2011 to 2016 in the same study ${ }^{107}$. Mcr-5 encodes a 547 amino acid PEtN transferase, which has a protein identity of 33\% to $35 \%$ to other known MCR proteins i.e., MCR-1 to MCR-4. Although MCR-5 has a low identity to other MCR proteins, all five MCR proteins, i.e., MCR1, MCR-2, MCR-3, MCR-4, and MCR-5, each encode the five conserved residue viz., E248, T286, H389, D458, and H359, that are located within the catalytic centre of the periplasmic domain ${ }^{107}$. These conserved residues have been found to be essential for substrate binding and MCR activity ${ }^{79}$. The capability of $m c r-5$ to confer colistin resistance was shown using the original $m c r-5$-harbouring plasmid and a plasmid vector encoding the $m c r-5$ operon in a transformation experiment using both an $E$. coli and a wild-type $S$. Paratyphi strains. In both experiments, the transformants achieved a colistin MIC value of $8 \mathrm{mg} / \mathrm{L}^{107}$.

The MCR-5 protein has a 100\% amino acid sequence identity to a PEtN transferase identified in Pigmentiphaga genus and Cupriavidus gilardii. The first 404 amino acids of the MCR-5 protein also have a high identity to a hypothetical protein from Pseudomonas aeruginosa ${ }^{107}$. Genetic analysis of $m c r-5$ found that the resistance gene is located within an operon encoding 
703 a Chromate $\mathrm{B}(\mathrm{ChrB})$ protein domain responsible for regulating the expression of $\mathrm{Chr}$ A for 704 chromate resistance and two ORF that encode a major facilitator superfamily (MFS) type 705 transporter ${ }^{107,108}$. The complete operon is located within a $7337 \mathrm{bp} \mathrm{Tn}-3$ type transposon 706 named Tn6452 52, 107, that is flanked by inverted repeats (IRs). A genetic analysis of the 707 transposon identified tnpA encoding a Tn 3 transposon, tnpR encoding a $\operatorname{Tn} 3$ resolvase and a 708 bla gene encoding a $\beta$-lactamase ${ }^{109}$. Tn6452 encodes mechanisms for transposition of the mcr-5 cassette, TnpA, and TnpR ${ }^{109}$, which allows the $m c r-5$ cassette to be transferred 710 between plasmids and chromosomes ${ }^{110}$.

711 Mcr-5 has also been identified on Tn3-like structures that encode the ChrB gene but lacked 712 the transposase gene and encoded an imperfect Tn3-like inverted repeats left (IRL) ${ }^{110-112}$. 713 This structure resembles features of a miniature inverted repeat transposable element, which 714 possess a left or right IRs but lacks a transposase gene ${ }^{111}$. Kieffer et al. (2019a) ${ }^{111}$ suggests 715 the acquisition of the $m c r-5$ cassette was through a transposition event and although the Tn3716 like structure lacks a transposase gene, it can still mobilise the cassette through a 717 nonautonomous transposition mechanism. The $m c r-5$ cassette has been identified on the host 718 chromosome ${ }^{107}$, a multicopy ColE-type plasmid ${ }^{107,110,112,113}$ and on an IncX plasmid ${ }^{110}$. 719 The presence of $m c r-5$ cassette on a multicopy plasmid (ColE-type) thus means multiple 720 copies of $m c r-5$ transposon will exist within the cell. Borowiak et al. (2017) ${ }^{107}$ found that there is a higher degree of colistin resistance $(8 \mathrm{mg} / \mathrm{L})$ in isolates harbouring ColE-type plasmids encoding $m c r-5$ than in isolates with a single copy of the mcr-5 integrated within the chromosome $(4 \mathrm{mg} / \mathrm{L})$. The ColE type plasmids are, however, non-conjugative and thus

724 the presence of the $m c r-5$ cassette on an IncX plasmid allows for horizontal transfer and 725 dissemination of resistance gene between different bacterial genera and species ${ }^{109,111}$.

Mcr-7 variant

Mcr-7.1 was first identified in chicken in China ${ }^{114}$. It has thereafter been identified in environmental samples ${ }^{115,116}$ and faecal samples in Brazil ${ }^{117}$. The putative PEtN transferase has a $78 \%$ nucleotide sequence identity to part of the $m c r-3$ gene ${ }^{114}$. Genetic analysis of $m c r$ 7.1 identified a 381 bp ORF encoding the diacylglycerol kinase, $d g k A$, downstream of $m c r$ 7.1. The $d g k A$ has an $82 \%$ nucleotide sequence identity to Aeromonas ${ }^{114}$. Yang et al. (2018) 114 suggests, like $m c r-3$, mcr-7.1 originates from Aeromanas. This was derived based on the close genetic distance between MCR-3 and MCR-7.1 found during a phylogenetic analysis and the presence of $d g k A$ gene downstream both $m c r-3$ and $m c r-7.1$. The ORF sequence found upstream the $m c r-7.1$ gene has an $81 \%$ nucleotide sequence identity to a putative 
medRxiv preprint doi: https://doi.org/10.1101/2022.02.28.22271560; this version posted March 1, 2022. The copyright holder for this preprint (which was not certified by peer review) is the author/funder, who has granted medRxiv a license to display the preprint in perpetuity.

It is made available under a CC-BY-NC-ND 4.0 International license .

736 phosphodiesterase gene found in Aeromonas ${ }^{114}$. This evidence suggests that the Aeromonas

737 genus is a possible progenitor of $m c r-7.1$.

738 The mcr-7.1 encodes a 539 amino acid PEtN transferase that confers colistin resistance

739 during conjugative experiments ${ }^{114}$. The protein is made up of two domains, which resembles

740 a similar structure of MCR-3. Mcr-7.1 was identified on a self-transmissible IncI $_{2}$ type

741 plasmid with no ISs in its environment; hence, the dissemination of $m c r-7.1$ may be achieved

742 through plasmid mobilisation ${ }^{114}$.

743 Mcr-8 variant

744 Mcr-8 was initially identified in K. pneumoniae from a swine faecal sample in China ${ }^{118}$.

745 Conjugation assays found that it is a functional PEtN transferase and its expression resulted

746 in a four- and eight-fold increase in colistin MIC. ${ }^{118-120}$ MCR-8 mediated PEtN modification,

747 which was identified using a MALDI-TOF-based technique that discriminates between

748 colistin resistance mechanisms, i.e $m c r$-expression or chromosomal-mutations ${ }^{120}$. BLASTn

749 analysis showed that $m c r-8$ has a $50.23 \%$ nucleotide and $39.96 \%$ amino acid sequence

750 identity to part of $m c r-3$ but has $30 \%$ to $40 \%$ amino acid sequence identity to other MCR

751 proteins. Characterisation of MCR-8 using RaptorX predicted that MCR-8, like other MCR

752 proteins, is made up of two domains: domain one consisting of a five transmembrane $\alpha$-helix,

753 and domain 2 consisting of the putative catalytic centre ${ }^{118}$. Wang et al. (2018c) ${ }^{118}$ performed

754 sequence alignment of all eight MCR proteins and found that the active site residues (E246,

755 T285, K333, H395, D465, H466, E468, H478) necessary for enzyme activity of MCR

756 proteins and the six-cysteine residues required for the three disulphide bonds found in the

757 catalytic domain were highly conserved across all 8 MCR proteins ${ }^{118,119}$.

758 Analysis of $m c r-8$ 's genetic environment found that it is usually flanked by two complete

759 IS903 elements, with both 50 bp IRL and IRR located upstream, and downstream,

760 respectively ${ }^{119,121}$. It is also associated with ISEcll and ISKpn26, located upstream and

761 downstream, respectively ${ }^{122}$. Yang et al. (2019b) ${ }^{122}$ found that the insertion of ISEcl7 was

762 an independent event and may not be involved in mobilising $\mathrm{mcr}-8$. The formation of circular

763 intermediates via IS903B elements to mobilise mcr-8 remains unknown; however, the

764 association of $m c r-8$ to ISs facilitates both the transmission of $m c r-8$ and its close association

765 with other resistance genes ${ }^{121}$; specifically, it has been found associated with aminoglycoside

766 resistance genes ${ }^{121}$, $\beta$-lactamase genes ${ }^{119}$ and tmexCD1-toprJ1 genes that encode a novel

767 plasmid-mediated efflux pump that confers resistance to tigecycline ${ }^{123}$. 
768 Mcr-8 is commonly found in K. pneumoniae ${ }^{118,120,121,123-126}$, Wang et al. (2018c) ${ }^{118}$

769 performed a phylogenetic analysis of the $m c r$-positive $K$. pneumoniae isolates identified in

770 their study and found that the mcr-positive $K$. pneumoniae were genetically diverse.

771 K. pneumoniae express colistin resistance usually through chromosomal mutations ${ }^{10}$. Wu et

772 al. (2020) ${ }^{121}$ suggest the expression of $m c r-8$ may have synergistic effects with the

773 chromosomal mutations within the two-component system (TCSs), resulting in heterogenous

774 colistin resistance mechanisms ${ }^{121}$. Mcr-8 has also been identified in Klebsiella

775 quasipneumoniae ${ }^{122}$ and $R$. ornithinolytica as well as on a diverse range of Inc groups:

776 IncFII, IncFIA, IncFIB, IncQ, IncR, IncFIIK, IncFIA and IncA/C; these will expectedly

777 accelerate the dissemination of $m c r-8$ and other ARGs within and outside Enterobacteriaceae

$778119,121$.

779 Mcr-9 variant

780 Mcr-9 gene was identified by Carroll et al. (2019) ${ }^{127}$ in a colistin susceptible $S$.

781 Typhimurium isolated from a human patient in Washington State in 2010. A BLAST analysis

782 identified the gene in 355 genomes, where 65 were encoded on a plasmid replicon of the

783 same contig ${ }^{127}$. The presence of $m c r-9$ on a plasmid replicon facilitates its dissemination

784 globally and across Enterobacteriaceae ${ }^{127}$. It has thereafter been identified in more clinical

785 settings ${ }^{128-135}$ and in food-producing animals ${ }^{136,137}$. Among the 355 genomes, 65 were

786 associated with a plasmid replicon, which may facilitate their dissemination globally ${ }^{127}$. Mcr-

7879 cassette is usually located either on a $\mathrm{IncHI}_{2}$ and/or $\mathrm{IncHI}_{2 \mathrm{~A}}$ replicon or chromosomally

788 encoded ${ }^{127,133,138,139}$. It is widely distributed within Enterobacteriaceae, particularly within

789 Enterobacter sp. ${ }^{129,130,132,133,135}$, Citrobacter telavivum ${ }^{134}$, Salmonella sp. ${ }^{127,137,138}$ and E.

790 coli $^{136,140}$.

791 Mcr-9 is always associated with $w b u C$, encoding a cupin fold metalloprotein, located 792 downstream the gene ${ }^{131,135,140}$. The amino acid sequence of mcr-9 closely resembles that of $793 \mathrm{mcr}-3$ and $m c r-7$, at a $99.5 \%$ coverage; it has amino acid sequence identity of $64.5 \%$ to $\mathrm{mcr}$ 7943.17 and $63 \%$ to $m c r-7^{127,140}$. A three-dimensional structural model analysis of all nine $m c r$ 795 homologues based on the amino acid sequences of each showed that mcr-9 was closely 796 related to $m c r-3, m c r-4$ and $m c r-7$ at a structural level ${ }^{127}$. Further, all nine $m c r$-homologues 797 had a high level of conservation for both domains (transmembrane domain and catalytic 798 domain): the structural models showed the amino acids and structural elements were 799 conserved in the C-terminal catalytic domain and the structural elements in the membrane800 anchored N-terminal domain ${ }^{127}$. A database search using $m c r-9$ as a template identified a 
medRxiv preprint doi: https://doi.org/10.1101/2022.02.28.22271560; this version posted March 1, 2022. The copyright holder for this preprint (which was not certified by peer review) is the author/funder, who has granted medRxiv a license to display the preprint in perpetuity.

It is made available under a CC-BY-NC-ND 4.0 International license .

801

802

803

804

805

chromosomal-encoded mcr-9-like gene within a Buttiauxella species isolate, a member of the Enterobacteriaceae $^{140}$. The identified $m c r$-like protein, MCR-BG, was isolated from $B$. gaviniae, and was found to have an $84 \%$ amino acid identity to the MCR-9 enzyme; MCR$\mathrm{BG}$, similar to $m c r-9$, has the $w b u C$ gene located downstream ${ }^{140}$.

Similar results were reported by Yuan et al. (2019) with a PEtN transferase isolated from $B$. brennerae. It had $86.83 \%$ protein sequence identity to $m c r-9$ at a $100 \%$ coverage ${ }^{135}$. Further, the wbuC located adjacent the mcr-9 gene was found to be homologous to that of Buttiauxella with a $86 \%$ amino acid identity at a $98 \%$ coverage ${ }^{135}$. This evidence suggests that $m c r-9$ may have originated from Buttiauxella species and disseminated to the rest of the Enterobacteriaceae family.

The dissemination of $m c r-9$ may have been aided by its association with IS elements flanking the cassette ${ }^{133}$. The $m c r-9$ cassette has been found flanked with IS903 and IS903-like elements upstream as well as IS1R, IS26-like, and IS15DII located downstream in multiple reports $132,133,135,140$. The first report of the $m c r-9$ cassette encoded the wbuC gene, a TCS encoding $q s e C$ and $q s e B$ genes, $\triangle \mathrm{IS} 1 R$ and a remnant of $\Delta s i l R$, encoding a transcriptional regulatory protein, all of which are located downstream of the $m c r-9$ gene. The $m c r-9$ cassette is thereafter flanked by intact IS903 elements ${ }^{135}$. Though two copies of an intact IS element should be able to form a composite transposon or a circular intermediate, an inverse-PCR assay failed to detect any intermediates ${ }^{135}$. However, the identification of IS903-like elements associated with mcr-9 genes suggests the acquisition of the cassette through an IS903 dependent mechanism. In some reports, the 3'region of $m c r-9$ is adjacent to copS (three copper resistance membrane-spanning proteins that includes $r c n A, r c n R$ and a domaincontaining DUF4942) ${ }^{132,139}$.

The mcr-9 protein as stated above has high levels of conservation within both PEtN transferase domains ${ }^{127}$. Notwithstanding, multiple reports have shown $m c r$-9-harbouring isolates that are susceptible to colistin ${ }^{127,129,130}$, with the colistin MIC value usually less than $2 \mathrm{mg} / \mathrm{L}{ }^{128}$. Kieffer et al. (2019b) ${ }^{140}$ and Carroll et al. (2019) ${ }^{127}$ performed induction experiments that conferred clinical resistance. However, the mechanism underlining each experiment remains unknown. Carroll et al. (2019) identified a conserved $\sigma^{70}$ familydependent -35 and -10 regions and an inverted repeat in the promoter of $m c r-9$ genes in the database. The authors suggest that the conserved DNA motif in the mcr- 9 promoter is likely a recognition sequence for a transcription regulator, which might be needed for full expression 
833 of the $m c r-9$ gene ${ }^{127}$. Kieffer et al. (2019b) ${ }^{140}$ suggested the QseC-QseB TCS played a role

834 in inducing $m c r-9$ expression to confer colistin resistance in the presence of sub-inhibitory

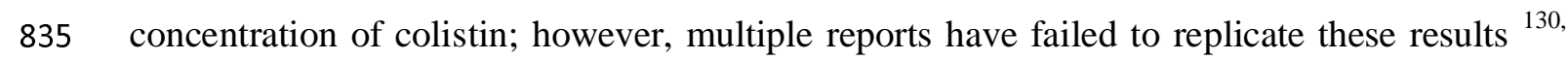
$836134,138,139$. In these studies, the mcr-9-harbouring isolates encoding the QseC-QseB TCS 837 regulatory genes were fully susceptible to colistin ${ }^{134,138}$. Tyson et al. (2020) ${ }^{138}$ suggests the 838 induction and overexpression of $\mathrm{mcr}-9$ may be context-dependent and be different in different 839 strain backgrounds. The expression of $m c r-9$ in a pBAD vector conferred colistin resistance 141 and Kieffer et al. (2019b) ${ }^{140}$ has shown that MCR-9 can mediate Lipid A modifications.

841 However, the genes and molecules required to regulate $m c r-9$ expression in its own genomic 842 environment remains unknown ${ }^{130}$.

Mcr-10 variant

The $m c r-10$ gene was first identified in an Enterobacter roggenkampii clinical strain in China 141 . It has a nucleotide sequence identity and amino acid sequence identity of $79.69 \%$ and $82.93 \%$ respectively to $m c r-9{ }^{141}$. Therefore, like $m c r-9$, the $m c r-10$ gene shares a significant amino acid identity to the chromosomally encoded mcr-like PEtN transferase of Buttiauxella species ${ }^{141}$. mcr-10 encodes a putative PEtN transferase that is made up of an N-terminal membrane-anchored domain and a C-terminal soluble catalytic domain, which have high levels of conservation to both MCR proteins and the MCR-B of various Buttiauxella species 141, 142. Xu et al. (2021) evaluated whether $m c r-10$ can mediate colistin resistance and compared its activity to that of $m c r-1$ and $m c r-9$. The study showed that the activity of $m c r-$ 10 against colistin is lower than that of $m c r-9$ but is able to mediate colistin resistance with an MIC value of $2.5 \mathrm{mg} / \mathrm{L}^{142}$. This shows that $m c r-10$ is functional and thus aids the host to survive colistin selective pressure ${ }^{142}$. Xu et al. (2021) again showed that the expression of mcr-10 is inducible under colistin resistance and further found an upregulation of $p h o P-p h o Q$ TCS genes, producing a colistin MIC value of $8 \mathrm{mg} / \mathrm{L}$. The authors suggested that $m c r-10$ might co-function with PhoPQ to mediate high levels of colistin resistance ${ }^{142}$.

Mcr-10 has been identified on IncFIA and IncFIB plasmids ${ }^{141-144}$ and adjacent to a XerC gene, which encodes a XerC type tyrosine recombinase found to mobilise adjacent genetic components such as antimicrobial resistance genes ${ }^{141}$. Thus, mer-10 would be presumed to 862 have disseminated across Enterobacteriaceae family but has only been identified commonly 863 in Enterobacter roggenkampii ${ }^{141,142,145}$ and once in Cronobacter sakazakii ${ }^{143}$. Wang et al. 864 (2020a) and Xu et al. (2021) suggest that E. roggenkampii is an important reservoir of $m c r$ 865 10. 
866 In the initial identification of $m c r-10$, the gene was adjacent XerC and flanked by two intact

867 IS903 elements which could form a composite transposon with the potential to mediate 868 mobilisation of the $m c r-10$ gene ${ }^{141}$. The analysis of the immediate genetic environment of 869 the IS903 element found the absence of direct repeats that are generated during an insertion 870 event; thus, the acquisition of the region bracketed by the IS903 elements was not due to an 871 insertion event ${ }^{141}$. The presence of an a $\triangle \mathrm{ISEC} 36$ downstream the $m c r-10$ gene was reported 872 to make it impossible to identify the recombination sites that the XerC-type tyrosine 873 recombinase recognizes ${ }^{141}$. Thus, the acquisition events of $m c r-10$ into pMCR-10_09006 874 remains unknown ${ }^{141}$. Mcr-10 has thereafter been ${ }^{145}$ identified with various insertion 875 sequences, including complete and truncated remnants of IS26 and ISKpn26, complete 876 sequences of ISEc36 and IS1, a $\triangle \mathrm{ISEcll-like} \mathrm{elements} \mathrm{and} \mathrm{recently,} \mathrm{a} \mathrm{new} \mathrm{IS} \mathrm{element}$ 877 designated ISCrsal ${ }^{143,145}$. The identification of various IS elements downstream $m c r-10$ $878 x \operatorname{xer} C$ suggests that this region might be a hotspot for insertions of MGEs ${ }^{141,142}$. The 879 acquisition of $m c r-10$ is presumed to be through site-specific recombination; ${ }^{143}$ however, 880 evidence of mobilisation of $m c r-10$ is scarce.

\section{Risk factors for acquiring mer genes}

882 Antimicrobials are commonly administered by farmers to pigs and poultry for prophylaxis, 883 therapeutics, and growth promotion in livestock ${ }^{146-148}$. Studies around the world have shown 884 that the use of colistin as a growth promoter results in a high frequency of $m c r-1$ positive, 885 colistin resistant Enterobacteriaceae (MPCRE) because of the high selective pressure in the 886 veterinary environment. The selection pressure led to the acquisition and spread of $m c r-1$ 887 genes ${ }^{11,146,148-152}$. The presence of $m c r-1$ in food animals had a serious potential to spread 888 MPCRE to humans via foodborne transmission ${ }^{11,150,151 .}$

889 The pharmaceutical form of colistin is indicated for oral administration and is present in a 890 powder or solution form ${ }^{152}$. Studies have shown that the drug is poorly absorbed in the 891 digestive tract after oral administration and can be excreted in high levels through the faeces $8921,150,152$. This results in the presence of colistin or its active metabolites in the environment 893 alongside the MPCRE isolates from the animal faeces ${ }^{150}$. Xia et al. (2019) ${ }^{153}$ measured the 894 concentration of colistin in animal feeds and fresh manure in five swine farms and found that 895 the average concentration of colistin in animal feed on farm 4 was $60 \mathrm{mg} / \mathrm{kg}$, which was 896 scientifically higher than other farms. The fresh manure samples collected on farm 4 had the 897 highest concentration of $17,383 \mu \mathrm{g} / \mathrm{kg}$. Other farms had colistin concentrations in their fresh 
898 manures ranging from $140 \mu \mathrm{g} / \mathrm{kg}$ in farms 1,2 and 5 , to $7,529 \mu \mathrm{g} / \mathrm{kg}$ in farm $3^{153}$. The researchers also discovered a strong relationship between colistin concentration and the relative abundance of $m c r-1$ genes in fresh manure ${ }^{153}$. The use of this manure as a fertilizer in agriculture or feeding farmed fish can result in the contamination of agriculture and, in some cases, the aquatic environment, polluting rivers and lakes ${ }^{150,154}$.

Luo et al. (2017) cultured an mcr-1 producing Raoultella ornithinolytica, a member of the Enterobacteriaceae family commonly found in soil, aquatic, and botanical environments, in retail vegetables in China. They emphasized that using animal excrements contaminated with colistin and/or MPCRE can cause contamination and spread of MPCRE to fresh vegetables. 154. There is, however, no epidemiological data on the contamination of rivers and lakes by MPCRE-contaminated animal excrements and thus, no evidence of the spread of MPCRE to the aquaculture ${ }^{150}$. However, the presence of $m c r$ - 1 -producing $E$. coli has been reported in duck and fish samples in China. Shen et al. (2019) ${ }^{155}$ found a potential spread of $\mathrm{mcr}-1$

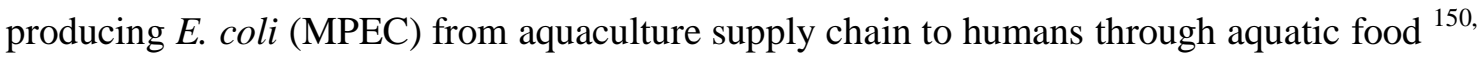
155. Other examples of the spread of MPCRE into the environment includes the identification and isolation of MPCRE in blowflies (Chrysomya sp.) ${ }^{156}$ and black kites ${ }^{54}$. Both cases are of public concern because of the potential transmission into human communities.

Yang et al. (2019a) ${ }^{156}$ showed that blowflies may serve as an environmental reservoir and vector of MPCRE between animals, humans, the environment, and waste (landfills and sewage water) ${ }^{156}$. The presence of MPCRE in Black kites in Russia highlights the spread of mcr-1 genes into both wildlife and the environment. Tarabai et al. (2019) ${ }^{54}$ hypothesized that the acquisition of MPCRE was either through contact with the Biysk Municipal landfill or through their food, which was commonly found along the Biya River near their nest. Black kites can thereafter spread MPCRE along their long migratory pathways ${ }^{54}$. The $m c r-1$ gene is commonly found on transferable plasmids, and thus the presence of $m c r-1$ producing isolates in the microbiota of insects and wildlife increases the possibility of horizontal transfer of mcr-1 genes alongside other resistance genes within the microbiota. This increases the environmental gene pool and the spread of multi-drug resistant (MDR) pathogens within insects and wildlife ${ }^{156}$.

927 There are therefore multiple reservoirs highlighted above with the potential of spreading towards humans because of the close association between humans and the environment. A study in Vietnam showed that the farmers that are in contact with animals under colistin selection pressure have a high risk of being colonized by MPCRE ${ }^{151}$. Trung et al. (2017) ${ }^{151}$ 
931 found that chickens associated with colistin administration had a high carriage of $m c r-1$ 932 producing isolates and the colonization of humans was through exposure to the chickens. The 933 chicken faecal samples had a high prevalence of $m c r-1$ (59.4\%) and zoonotic transmission 934 prevalence was $34.7 \%$ in farmers. Another possible route of transmission of MPCRE from 935 animals under colistin pressure was foodborne transmission 11, 157, 158. Monte et al. (2017a) 936 found that chicken meat was acting as a reservoir of MPEC. A study performed by Shen et al. 937 (2018) ${ }^{150}$ found a positive correlation between MPEC carriage in the human normal flora and 938 the consumption of farm animals, which included pork and sheep. The correlation analysis 939 also proposed a possible transmission of MPEC from aquatic food to humans ${ }^{150}$. This data is 940 a single example that highlights the presence of MPCRE in food-producing animals and the 941 transmission route of MPCRE from colistin-exposed animals to humans, which impacts 942 public health care.

943 This therefore led to the ban on colistin use for growth promotion and disease prevention in 944 the food industry to preserve their effectiveness in human medicine as their use contributes to 945 the rising threat of antibiotic resistance ${ }^{159}$. Randall et al. (2018) ${ }^{160}$ also demonstrated that 946 discontinuing colistin in farming can result in the elimination of $m c r-1$. This longitudinal 947 study evaluated the presence of $m c r-1$ in pig faeces and slurry at two time points ${ }^{160}$. At the 948 beginning of the study, the majority of the pigs were colonized by MPEC. Twenty months 949 after cessation of colistin use and implementation of hygiene and other measures, MPEC was 950 not detected in samples. These results thus highlight that the use of colistin is the driving 951 force behind the spread of colistin resistance genes and its stability in the population ${ }^{160}$. The 952 integration of $m c r-1$, however, into conjugative plasmids encoding other resistance genes 953 allows for the use of other antibiotics such as quinolones and extended spectrum 954 cephalosporins to simultaneously co-select for $m c r-1$, allowing for its stability and 955 dissemination ${ }^{146,161,162}$. This, thus, creates severe challenges for controlling the selection and 956 subsequent transmission of $m c r-1$ genes ${ }^{163}$.

957 After the first detection of $m c r-1$ by Liu et al. (2016), $m c r-1$ genes have been detected in 958 animals, the environment, and humans. Initially, the detection of $m c r-1$ genes in humans was 959 associated with the risk factors mentioned above: contact with farm animals, ingestion of 960 contaminated farm food, or fresh vegetables. Epidemiology studies that identified $\mathrm{mcr}-1$ 961 genes in the clinical settings were accompanied with a questionnaire to identify the 962 epidemiological exposure. In countries such as Finland, where the use of colistin is restricted 963 for rare clinical indications, the first detection of the $m c r-1$ gene was identified in a healthy 
964 male with previous history of travelling abroad, 6 months before faecal sampling ${ }^{164}$.

965 Traveling to other countries has been shown to increase the risk of acquiring mor-1 positive

966 isolates, particularly in patients who consumed meat while traveling abroad ${ }^{164,165}$. The use of

967 antibiotics prior to hospitalization or infection has been seen as an important risk factor for a

968 multidrug resistant organism (MDRO) infection ${ }^{165}$. An epidemiological and clinical study

969 performed by Wang et al. (2017) ${ }^{166}$ discovered that MPEC can acquire other resistance

970 genes, and thus previous use of antibiotics such as carbapenems and fluroquinolones was

971 associated with an increased risk of infection by MPEC ${ }^{166}$. Thus, the administration of

972 antibiotics in clinics simultaneously promotes the co-selection and the preservation of colistin

973 resistance genes ${ }^{167}$.

974 An interesting possible transmission of MPEC is between companion animals and humans. A 975 worker at a pet shop with no prior antibiotic use or travelling abroad was identified carrying 976 an MPEC ${ }^{168}$. A faecal screening of the pets residing where the man worked identified 4 dogs 977 and 1 cat with an $m c r-1$ positive isolate. Zhang et al. (2016) ${ }^{168}$ suggested companion animals 978 as a possible reservoir of colistin-resistant E. coli, facilitating the spread of colistin resistance 979 genes within the community.

\section{Current and future perspectives on treating mcr-mediated colistin resistance}

982 Clustered regularly interspaced short palindromic repeats (CRISPR) has been exploited and 983 developed within molecular biology as a site-specific tool for genetic engineering ${ }^{169}$, and in 984 regards to resistance, as a tool to deliver a programmable DNA nuclease (CRISPR-Cas9) into 985 an MDR-pathogen to eliminate the resistance gene or plasmid ${ }^{170}$. Dong et al. (2019) ${ }^{170}$ 986 developed a conjugative CRISPR-Cas9 system that aimed to remove plasmids harbouring the 987 mcr-1 gene from bacteria. The system targeted the $m c r-1$ gene and the authors found that the 988 formation of DSBs during the elimination of the resistance gene resulted in the elimination of 989 the whole plasmid in recipient cells ${ }^{170}$. This thereafter sensitized the recipient cells to 990 colistin. Dong et al. (2019) ${ }^{170}$ further found that the cells are thereafter immune against the 991 mcr-1 gene. Wang et al. (2019a) ${ }^{171}$ used the same concept but developed the tool to remove 992 both $m c r-1$-harbouring plasmids and MDR plasmids present in recipient cells using partial 993 sequences of the targeted plasmids. He et al. (2021) ${ }^{172}$ used the tool to eliminate both 994 chromosomal and plasmid-borne mcr-1 genes in E. coli. The CRISPR-Cas9 system was 995 designed to target ISApl1, which eliminated $m c r-1$ harbouring plasmids, and in the case of 996 chromosomally encoded $m c r-1$, cell death was seen. Similar results were achieved ${ }^{170}$, where 
997

998

999

1000

1001

1002

1003

1004

1005

1006

1007

1008

1009

1010

1011

1012

1013

1014

1015

1016

1017

1018

1019

1020

1021

1022

1023

1024

1025

1026

1027

recipient cells further acquired immunity against the acquisition of the exogenous mcr-1 containing plasmid ${ }^{172}$. These studies show that CRISPR-Cas9 system is an efficient tool for plasmid curing and to sensitise clinical isolates to antibiotics in vitro ${ }^{170,171}$. This tool can be optimized for therapeutic application for the elimination of antibiotic genes from resistance reservoirs such as animal guts with prior exposure to antibiotics, the human microbial flora or the bacteria in natural settings such as wastewater, farms or hospital settings ${ }^{170}$.

The CRISPR-Cas9 system is however made up of highly anionic nucleic acids and proteins that cannot penetrate the cell membrane into cells and thus requires a delivery vehicle. Sun $e t$ al. (2017c) ${ }^{173}$ explored Cathelicidins, which are short cationic antimicrobial peptides, as a plasmid delivery system. The study evaluated the use of BMAP-27 to increase the efficiency of plasmid transfer of the CRISPR-Cas9 system and found that pCas::mcr exhibited better, efficient, and specific antimicrobial effects with the help of BMAP-27 ${ }^{173}$. The CRISPR-Cas9 system is a powerful tool for genome editing, its development into targeting multiple genes with one use ${ }^{171}$, could aid in the removal of $\mathrm{mcr}$ variants in resistance reservoirs and in clinical settings to restore colistin activity.

In the meantime, there are multiple studies evaluating existing antibiotics for activity against mcr-producing isolates and synergy combinations.

\section{Novel antibiotics}

There are multiple novel antibiotics that have been found to have activity against $m c r-1$ producing isolates, including eravacycline ${ }^{6,174}$ and plazomicin ${ }^{175}$. Eravacycline is a broadspectrum synthetic tetracycline that has been proven to be effective against clinically important MDR pathogens, including both Gram-negative and gram-positive bacteria ${ }^{174}$. Fyfe et al. (2016) ${ }^{6}$ found that eravacycline had a bactericidal effect against mor-producing isolates from Enterobacteriaceae. The study further showed that although the overexpression of $m c r-1$ increased colistin MIC values by 64 -folds, there was no effect on eravacycline susceptibility ${ }^{6}$. Eravacycline activity was thereafter evaluated against 336 isolates collected from hospitals across China and was found to exhibit a good efficacy against all strains ${ }^{174}$. These isolates included Extended spectrum $\beta$-lactamase (ES $\beta$ L) and carbapenemaseproducing Enterobacteriaceae, mcr-producing Enterobacteriaceae and A. baumannii, vancomycin-resistant Enterobacteriaceae, $\beta$-lactamase producing Haemophilus influenzae, penicillin-resistant Streptococcus pneumoniae and lastly, methicillin-resistant Staphylococcus 
medRxiv preprint doi: https://doi.org/10.1101/2022.02.28.22271560; this version posted March 1, 2022. The copyright holder for this preprint (which was not certified by peer review) is the author/funder, who has granted medRxiv a license to display the preprint in perpetuity. It is made available under a CC-BY-NC-ND 4.0 International license .

1028

1029

1030

1031

1032

1033

1034

1035

1036

1037

1038

1039

1040

1041

1042

1043

1044

1045

1046

1047

1048

1049

1050

1051

1052

1053

1054

1055

1056

1057

1058 aureus (MRSA), thus showing a positive potential to treat current drug-resistant bacterial infections ${ }^{174}$. This, however, also puts eravacycline at risk of being overused.

Plazomicin is a novel broad-spectrum semi-synthetic aminoglycoside that was derived from Sisomicin. It has been shown to have activity against a broad spectrum of MDR pathogens, including ES $\beta \mathrm{L}$ - and carbapenemase-producing isolates and fluroquinolone-resistant isolates 175. Denervaud-Tendon et al. (2017) ${ }^{175}$ evaluated the bactericidal activity of plazomicin against colistin-resistant Enterobacterial strains, which harboured different colistin resistance mechanisms i.e., chromosomal-encoded, $m c r-1$-expressing, and intrinsically resistant strains. Plazomicin activity was further compared with other aminoglycoside antibiotics viz., amikacin, gentamicin, and tobramycin. Plazomicin displayed potent activity against the clinical colistin-resistant Enterobacterial strains irrespective of their resistance mechanisms. However, those that were intrinsically resistant (Serratia, Proteus, Morganella and Hafnia) had a higher MIC value ${ }^{175}$.

Denervaud-Tendon et al. (2017) also found that amongst all aminoglycoside antibiotics tested, plazomicin was the most potent. They lastly also found that plazomicin's activity is restricted by aminoglycoside resistance mechanisms such as the $16 \mathrm{~S}$ rRNA methylaseencoding gene, which resulted in an elevated plazomicin MIC value (>128 mg/L). Plazomicin, however, like other aminoglycosides, has a rapid bactericidal activity with favourable chemical and pharmacokinetics properties and thus could be incorporated into therapeutic treatments against $m c r$-producing bacterial infections ${ }^{175}$.

Artilysin ${ }^{\circledR}$ Art-175 is a novel engineered enzyme-based experimental therapeutic derived from endolysins produced by lytic bacteriophages. These endolysins degrade the bacterial cell wall resulting in cell lysis, which occurs at the end of the bacteriophage infection cycle 176. Artilysin $®$ Art-175 is made up of the outer membrane destabilizing peptide, which is fused to an endolysin, it targets the anionic lipopolysaccharide molecules of the outer membrane of Gram-negatives. Schirmeier et al. (2018) ${ }^{177}$ evaluated the potential of Art-175 against pan-drug resistant isolates, including colistin-resistant MPEC and further determined the potential of cross-resistance between colistin and Art-175. Art-175 was highly bactericidal against the tested isolates, which were more susceptible to Art-175 than the colistin-susceptible isolates ${ }^{177}$. Hence, there is no cross-resistance between the two peptides, highlighting Art-175 as a potent solution against mcr-producing isolates ${ }^{177}$. 
medRxiv preprint doi: https://doi.org/10.1101/2022.02.28.22271560; this version posted March 1, 2022. The copyright holder for this preprint (which was not certified by peer review) is the author/funder, who has granted medRxiv a license to display the preprint in perpetuity.

It is made available under a CC-BY-NC-ND 4.0 International license .

1059

1060

1061

1062

1063

1064

1065

1066

1067

1068

1069

1070

1071

1072

1073

1074

1075

1076

1077

1078

1079

1080

1081

1082

1083

1084

1085

1086

1087

1088

1089

1090

1091

\section{Antimicrobial peptides}

Bacteriocins are ribosome-synthesized antimicrobial peptides (AMPs) produced by both Gram-positive and Gram-negative bacteria. Studies have shown that bacteriocins produced by lactic acid bacteria (LAB) are cationic peptides with bactericidal activity that act on the cytoplasmic membrane of susceptible microorganisms ${ }^{178}$. The LAB bacteriocins create pores in the membrane, resulting in intracellular damage. Al Atya et al. (2016) ${ }^{4}$ evaluated the combinations of nisin and enterocin DD14 LAB bacteriocins with colistin to eradicate colistin-resistant E. coli strains in either planktonic states or in biofilm. Whilst colistin and the bacteriocins were ineffective as monotherapy against both planktons and biofilms, colistin-nisin and colistin-enterocin DD14 combination were able to reduce the number of colony-forming units (CFU) of strains in both planktonic and biofilm states. The triple combination of all three molecules, colistin-nisin-enterocin DD14, completely eradicated all E. coli strains, including colistin-resistant phenotype ${ }^{4}$. LAB bacteriocins alone cannot penetrate the outer membrane. However, with the disruption of the LPS via colistin activity, the LAB bacteriocins may thereafter act upon the cytoplasmic membrane ${ }^{4}$. Al Atya et al. $(2016){ }^{4}$ therefore highlights LAB bacteriocins as a potential novel adjunctive treatment for colistin-resistant MPEC infections.

There have been multiple reports of AMPs that have been developed for treating MDR pathogens, which have a similar mode of action as colistin ${ }^{179}$. Van der Weider et al. (2019) evaluated the antimicrobial activity of two novel AMPs, AA139 and SET-MM3. AA139 originates from a marine lugworm, Arenicola marina, AMP arenicin-3. SET-MM3 is a synthetic tetra-branched peptide linked by a lysine core ${ }^{179}$. The antimicrobial activity of these AMPs was evaluated against a collection of clinically and genotypically diverse $K$. pneumoniae with different antimicrobial susceptibility profiles. Both AMPs, AA139 and SET-M33, further showed a concentration-dependent bactericidal effect across all isolates, meaning that the susceptibility profile of both AMPs was unaffected by the resistance profile and colistin susceptibility of the isolates ${ }^{179}$. The AMPs were effective against the colistinresistant strains, and no cross-resistance was observed between the AMPs and colistin. Thus the antimicrobial activity of AA139 and SET-M33 should further be investigated across other Gram-negatives to evaluate its spectrum of bactericidal activity ${ }^{179}$.

Cross-resistance between several human cationic AMPs (CAMPs) and polymyxins has been previously reported in PEtN transferase-producing Haemophilus ducreyi and Campylobacter jeyuni but rarely in Enterobacteriaceae. These CAMPs are part of the intrinsic human 
medRxiv preprint doi: https://doi.org/10.1101/2022.02.28.22271560; this version posted March 1, 2022. The copyright holder for this preprint (which was not certified by peer review) is the author/funder, who has granted medRxiv a license to display the preprint in perpetuity. It is made available under a CC-BY-NC-ND 4.0 International license .

1092

1093

1094

1095

1096

1097

1098

1099

1100

1101

1102

1103

1104

1105

1106

1107

1108

1109

1110

1111

1112

1113

1114

1115

1116

1117

1118

1119

1120

1121

1122

1123

1124

immune system and act against Gram-negative bacteria by disrupting the outer and inner membrane through electrostatic interaction, similar to colistin's mechanism of action ${ }^{180}$. Dobias et al. (2017) ${ }^{180}$ selected a few widely distributed CAMPs in humans, LL-37, $\alpha-$ defensin 5 (HD5) and $\beta$-defensin 3 (HDB3) and evaluated whether cross-resistance between CAMPs and polymyxin would be observed in MPEC. Susceptibility of $E$. coli to the different CAMPs selected varied depending on the CAMP molecule rather than the entire CAMP family. It further showed that the production of MCR proteins did not confer cross-resistance with the human CAMPs selected ${ }^{180}$.

However, the CAMPs activity studied by Dobias et al. (2017), ${ }^{180}$ compared to other studies ${ }^{181}$, shows that factors such as bacterial species, level of resistance, and colistin resistance mechanisms may affect the bactericidal levels of CAMPs ${ }^{180,181}$. Therefore, although $m c r$ production did not affect the bactericidal activity of CAMPs against $E$. coli, it needs to be evaluated across Enterobacteriaceae and other Gram-negative bacteria to see how different colistin resistance mechanisms affect the CAMPs' bactericidal effect. Guachalla et al. (2018) 182 further evaluated the effectiveness of other derivates of the human immune system against a clinical MPEC strain. This includes humanized monoclonal antibodies that have been previously shown to target the LPS O25b antigen that is associated with E. coli ST131-H30 182. The expression of $m c r-1$ does not affect the binding of ASn-4 to the LPS's O-antigen and the integration of the complement membrane-attack complex (MAC) into the LPS-modified outer membrane ${ }^{182}$. This means the expression of $m c r-1$ in $E$. coli ST131-H30 does not affect the functionality of the human immune system, nor does it not aid the strain via immune evasion. The authors thereafter suggested the use of antibodies targeting the LPS's O-antigen as an alternative strategy to combatting MDR infections against $m c r-1$ positive isolates ${ }^{182}$.

Other novel compounds produced to manage mcr-producing isolates are antisense agents with antimicrobial properties; this include phosphorodiamidate morpholino oligomers (PPMOs) and peptide nucleic acids (PNAs) ${ }^{183}$. These antisense molecules are designed to target mRNA, prevent translation, and restore antimicrobial sensitivity. Daly et al. (2017) ${ }^{184}$ designed peptide-conjugated PPMOs targeted to mcr-1 mRNA (MCR-1 PPMO) of clinical mcr-1-positive E. coli strains and showed that these molecules were able to make the strains re-sensitive to polymyxins by $M C R-1$ inhibition ${ }^{184}$. Similar results were achieved by Nezhadi et al. (2019) ${ }^{183}$ with PNAs, designed for inhibition of $m c r-1$ translation. They ${ }^{183}$ showed that the introduction of PNA resulted in a $95 \%$ reduction of $m c r-1$ expression, measured by RTPCR, highlighting the efficacy of PNAs ${ }^{183}$. Daly et al. (2017) ${ }^{184}$ evaluated the antisense 
medRxiv preprint doi: https://doi.org/10.1101/2022.02.28.22271560; this version posted March 1, 2022. The copyright holder for this preprint (which was not certified by peer review) is the author/funder, who has granted medRxiv a license to display the preprint in perpetuity.

It is made available under a CC-BY-NC-ND 4.0 International license .

1125

1126

1127

1128

1129

1130

1131

1132

1133

1134

1135

1136

1137

1138

1139

1140

1141

1142

1143

1144

1145

1146

1147

1148

1149

1150

1151

1152

1153

1154

1155

approach in a sepsis model using mice and found that a combined therapy of MCR-1 PPMO with colistin reduced morbidity and bacterial burden in the spleen at $24 \mathrm{hr}$. Thus, antisense agents may be effective therapeutics, either alone by targeting an essential gene resulting in cell death, ${ }^{184}$ or in combination with colistin 183,184 to treat mcr-1-producing isolates. However, these molecules have varying toxicity effects and more in-vivo research is required prior to clinical application ${ }^{183}$.

\section{Natural compounds}

Other novel compounds that have been reported to restore susceptibility of polymyxins in mcr-1 producing isolates includes the novel MCR-1 inhibitor, Osthole (7-methoxy-8-(3methyl-2-buteryl) coumarin. Osthole (OST) is a natural compound derived from the dried root and rhizome of Cnidium monnieri ${ }^{185}$. Zhou et al. (2019) ${ }^{185}$ evaluated the effects of OST on the inhibition of MCR-1 enzyme and the mechanisms behind the inhibition. The colistin-OST combination had a synergistic effect as a mouse-thigh-infection model showed that the combination exhibits a bactericidal activity against mcr-1-producing Enterobacteriaceae, significantly reducing the bacterial load in the thighs following subcutaneous administration ${ }^{185}$. Using a molecular dynamic stimulation, Zhao et al. (2019) 185 found that OST could localize in the binding pocket (residue 330-350) of MCR-1, blocking the substrate and reducing MCR-1's biological activity. OST therefore inhibits MCR-1 in Enterobacteriaceae, making colistin potent ${ }^{185}$. Due to the conservation of MCR proteins, OST may have the same inhibition efficiency across the other MCR variants.

Natural/organic compounds identified with a synergistic effect on colistin include Honokiol ${ }^{186}$, Isoalantolactone (IAL) ${ }^{187}$, Calycosin ${ }^{188}$ and Eugenol ${ }^{189}$. Honokiol was derived from the dry skin and bark of Magnolia officinalis ${ }^{186}$, IAL is the main sesquiterpene lactone from Radix inulae and other plants ${ }^{187}$, Calycosin is a flavonoid from a direct root extract of the traditional Chinese medicinal herb, Radix astragali. ${ }^{188}$ Lastly, Eugenol is a phenylpropanoid, an essential oil isolated from plants ${ }^{190}$. Each of these compounds, when combined with colistin, decreased colistin MICs and increased colistin's bactericidal activity against colistinresistant isolates. Eugenol decreased the expression of $m c r-1^{189}$ and honokiol bound directly to the active site of MCR-1, inhibiting its activity ${ }^{186}$. Guo et al. (2020) ${ }^{186}$ and Liu et al. (2020) ${ }^{188}$ showed that the natural compounds, honokiol and calycosin, in combinations with colistin, respectively reduced the load of bacteria and improved viability in animal models. 
medRxiv preprint doi: https://doi.org/10.1101/2022.02.28.22271560; this version posted March 1, 2022. The copyright holder for this preprint (which was not certified by peer review) is the author/funder, who has granted medRxiv a license to display the preprint in perpetuity.

It is made available under a CC-BY-NC-ND 4.0 International license .

\section{Efflux pump inhibitors}

Efflux pumps play a role in reducing colistin susceptibility in Enterobacteriaceae ${ }^{10}$. Baron et al. (2018) ${ }^{191}$ found that an efflux pump inhibitor, carbonyl cyanide 3-chlorophenylhydrazone (CCCP), was a good alternative to reverse colistin resistance in colistin-resistant isolates irrespective of their molecular resistance mechanisms. The study shows that CCCP was able to restore colistin activity across a diverse set of strains carrying different colistin resistance mechanisms ( $m c r-1, p m r A B, \operatorname{mgrB}$, etc) ${ }^{191,192}$. In $m c r-1$ producing isolates, it was seen that colistin-CCCP combination inhibited the transcription of the $m c r-1$ gene. The mechanism behind this observation, however, is unknown ${ }^{191}$.

\section{FDA-approved drugs}

The food and drug administration (FDA) has a library of FDA-approved drugs that can be screened for bactericidal activity on mcr-producing Enterobacteriaceae isolates (Prestwick Chemical, Illkirch-Graffenstuden, France). Multiple compounds such as pentamidine, zidovudine ${ }^{193}$, sulphonamide compounds ${ }^{193}$, a polymyxin derivative, NAB739, ${ }^{194}$ and compound PFK-185, ${ }^{194}$ have been identified during a library search.

Zidovudine is a nucleoside reverse transcriptase inhibitor. In the 1980s, it was used as an anticancer drug ${ }^{195}$. In 1986, its antibacterial effect was revealed ${ }^{196}$ and in 1987, it was used as the first antiretroviral for treatment against HIV infections ${ }^{195,197}$. Peyclit et al. (2018) ${ }^{197}$ investigated the antibacterial activity of Zidovudine against a large number of characterised MDR Enterobacteriaceae strains isolated from different geographical areas, including carbapenem- and colistin-resistant isolates; Zidovudine was effective against Enterobacteriaceae. Despite their antimicrobial susceptibility profile, the MIC values ranged between $0.05-1.67 \mu \mathrm{g} / \mathrm{mL}^{197}$.

Another antiretroviral drug that is used to treat HIV/AIDS but also has bactericidal activity against Gram-negative bacteria is Azidothymidine (AZT). Hu et al. (2019) ${ }^{198}$ shows that AZT, in combination with colistin, was able to eradicate MDR Enterobacteriaceae strains with different antimicrobial susceptibility profiles and enhance the activity of colistin. The combined therapy was also effective therapeutically in a murine peritoneal infection against NDM-1-producing K. pneumoniae and MPEC ${ }^{198}$.

Further, Pentamidine is an antiprotozoal drug that Stokes et al. (2017) ${ }^{199}$ identified as an effective antibiotic adjuvant producing synergistic combination activity against a wide range of Gram-negative bacteria. The adjuvant was identified during a library screening of non- 
medRxiv preprint doi: https://doi.org/10.1101/2022.02.28.22271560; this version posted March 1, 2022. The copyright holder for this preprint (which was not certified by peer review) is the author/funder, who has granted medRxiv a license to display the preprint in perpetuity.

It is made available under a CC-BY-NC-ND 4.0 International license .

1188 lethal, outer membrane-active compounds ${ }^{199}$. The study shows that Pentamidine directly 1189 associates with the outer membrane by inhibiting the oligosaccharide (OS) core biosynthesis, 1190 releasing LPS from the outer membrane ${ }^{199}$. Stokes et al. (2017) ${ }^{199}$ further showed that 1191 Pentamidine has synergistic activity with hydrophobic antibiotics such as rifampicin, 1192 novobiocin, and erythromycin but not with hydrophilic and low-molecular weight antibiotics $1193{ }^{199}$. Although the study does not evaluate synergistic combinations with Pentamidine, Stokes 1194 et al. (2017) ${ }^{199}$ concluded that pentamidine can be used as an antibiotic adjuvant for treating 1195 colistin-resistant infections.

1196 Barker et al. (2017) ${ }^{200}$ screened a diverse cohort of adjuvants to identify a compound that 1197 could both sensitise colistin-resistant and hypersensitise colistin-susceptible bacteria to 1198 colistin, to potentially lower the effective dosage of colistin, reducing its toxicity. The study 1199 identified three compounds that were potent modulators of colistin resistance and were able 1200 to significantly reduce MIC values in both plasmid- and chromosomal-mediated resistance 1201 mechanisms, and further hypersensitize colistin-susceptible isolates ${ }^{200}$

1202 Another compound identified in the FDA-approved library with synergistic activity with 1203 colistin is sulfadiazine (SDI), a sulphonamide compound. Okdah et al. (2018) ${ }^{193}$ evaluated 1204 the potential of different sulphonamide compounds with potential synergistic and bactericidal 1205 activity in combination with colistin; SDI had the highest synergistic effect. The combination 1206 of SDI-colistin was effective, independent of colistin resistance mechanism, across the broad 1207 range of MDR bacterium strains tested ${ }^{193}$.

1208 Zhang et al. (2019) ${ }^{194}$ identified an antitumor drug, PFK-185 and its analogs, PFK-015 and $12093 \mathrm{PO}$, during a screening of the clinical compound library. These compounds can exert 1210 synergise with colistin against colistin-resistant Enterobacteriaceae despite mer expression 1211 and the antimicrobial susceptibility profile ${ }^{194}$. Zhang et al. (2019) ${ }^{194}$ found that PFK-185 1212 had no effect on cellular morphology when used alone. However, when in combination with 1213 colistin, it enhanced the bacterium-killing effect of colistin, increasing the survival rate to $121460 \%$. The combined colistin-PFK-158 therapy had the most significant bactericidal activity, 1215 with the most significant reductions in the bacterial burdens post-in vivo experiments and 1216 during time-kills studies. ${ }^{194}$.

1217 The last compound reported from the FDA-approved library is a novel polymyxin derivative, 1218 NAB739, which carries only three of the five amino groups of colistin, each placed in a 1219 strategic position ${ }^{201}$. Tyrrell et al. (2019) ${ }^{201}$ showed that NAB739 sensitizes polymyxin- 
medRxiv preprint doi: https://doi.org/10.1101/2022.02.28.22271560; this version posted March 1, 2022. The copyright holder for this preprint (which was not certified by peer review) is the author/funder, who has granted medRxiv a license to display the preprint in perpetuity.

It is made available under a CC-BY-NC-ND 4.0 International license .

1220

1221

1222

1223

1224

1225

1226

1227

1228

1229

1230

1231

1232

1233

1234

1235

1236

1237

1238

1239

1240

1241

1242

1243

1244

1245

1246

1247

1248

1249

1250 resistant strains to rifampicin and a combination of the two was synergistic against ten of the eleven colistin-resistant strains. Tyrrell et al. (2019) ${ }^{201}$ further showed that NAB739 was also synergistic with meropenem and retapamulin. As well, NAB739 in combination with other compounds has significant bactericidal activity against polymyxin-resistant isolates and compared to polymyxins, it has a better tolerability and efficacy ${ }^{201}$. Thus, NAB739 combination therapies may replace polymyxin for treating MDR pathogens ${ }^{201}$.

These studies 197, 199 however, show that old antimicrobials listed within the FDA-approved library may be re-introduced against bacteria that are resistant to multiple antibacterials in current use ${ }^{197}$.

\section{Combination therapy}

There are multiple compounds, either antibiotics or adjuvants, which are synergistic with colistin, thus reducing the dosage of colistin required for treatment, minimizing its toxicity, overcoming colistin resistance, and retaining maximal therapeutic efficacy ${ }^{198,200}$. Colistin activity has been restored when it is combined with antibiotics such as rifampicin 202, 203, rifabutin, minocycline ${ }^{203}$, amikacin ${ }^{204}$, tigecycline ${ }^{205}$ and clarithromycin ${ }^{206}$. In all these reports, the antibiotics were ineffective as monotherapy against MPCRE isolates. However, in combination with colistin, they resulted in significant bactericidal activity. Yu et al. (2019) 203 found that colistin in combination with rifampicin, rifabutin or minocycline was able to eradicate XDR, NDM- and mcr-co-producing E. coli in-vitro and in mouse models. Other combinations that were confirmed effective against $\mathrm{mcr}$-1-producing colistin-resistant $E$. coli using an animal model include tigecycline-colistin ${ }^{205}$, clarithromycin-colistin ${ }^{206}$ and a triple combination of colistin-rifampin-azithromycin discovered by Li et al. (2018b) ${ }^{202}$. Another triple combination therapy that was discovered was colistin-aztreonam-amikacin, which was effective against both carbapenemase-producing and $m c r$-1-producing Enterobacteriaceae isolates ${ }^{207}$.

Lastly, a combination therapy that was effective against both carbapenem- and colistinresistant Enterobacteriaceae isolates was the $\beta$-lactam- $\beta$-lactamase inhibitor, imipenemrelebactam, combination ${ }^{208}$. This combined therapy was potent against colistin-resistant carbapenemase-producing isolates, making it a potential agent against carbapenemaseproducing Enterobacteriaceae; particularly, those that are colistin resistant (irrespective of the mechanism of resistance) ${ }^{208}$. 
medRxiv preprint doi: https://doi.org/10.1101/2022.02.28.22271560; this version posted March 1, 2022. The copyright holder for this preprint (which was not certified by peer review) is the author/funder, who has granted medRxiv a license to display the preprint in perpetuity.

It is made available under a CC-BY-NC-ND 4.0 International license .

1251

1252

1253

1254

1255

1256

1257

1258

1259

1260

1261

1262

1263

1264

1265

1266

1267

1268

1269

1270

1271

1272

1273

1274

1275

1276

1277

1278

1279

1280

1281

1282

1283

Conclusion

Herein, we show that $m c r$ genes are commonly identified in E. coli, K. pneumoniae, and Salmonella sp., with clones within these strains being disseminated globally within animals, food, the environment, and humans. Mcr genes were initially identified in animal samples, specifically livestock animals that were treated with colistin as a therapeutic against Gramnegative bacterial infections or as a growth promoter. $\mathrm{Mcr}$ has spread to the environment through contaminated but untreated animal faeces used as manure and through contaminated food-producing-animals' products on markets. Contact with these colistin-treated livestock or their faeces by humans was an identified transmission route. Human specimens currently have the highest reports of $\mathrm{mcr}$ genes due to the multiple routes of transmission from livestock, the environment and from food, and the use of colistin as a therapeutic against carbapenem-resistant Enterobacteriaceae infections. The presence of clones such as E. coli ST744 or ST101 in all sources, including animals, the environment, food, and humans, highlights these transmission routes. This makes $\mathrm{mcr}$ a concerning antibiotic resistance gene of great interest and priority.

Further, $m c r$ genes are commonly associated with mobile genetic elements. ISApll elements have facilitated the horizontal transfer of $m c r-1$ within cassettes of composite transposons. They have been also associated with $\mathrm{IncX}_{4}$ plasmids, facilitating their horizontal and vertical transfer across species, genera and families.

Although the mor variants have different possible progenitors viz., Moracella sp., Aeromonas sp., and Shewanella sp. for $m c r-1, m c r-3$ and $m c r-4$, respectively, the MCR proteins are very well conserved. Each of the $10 \mathrm{MCR}$ proteins encodes a two-domain integral membrane protein with a C-terminal periplasmic domain and an N-terminal 5'-helix transmembrane domain, each MCR protein further encodes the five conserved residues i.e., E248, T286, $\mathrm{H} 389$, D458, and H359, located within the active site. PEtN transferase activity was found for each MCR protein, and each was able to mediate colistin resistance, although $\mathrm{mcr}$-9 expression requires a specific genetic environment to regulate its expression. The conservation seen within MCR proteins, allows for the use of similar therapies for the management of MCRPE isolates, specifically in the cases of identified MCR-1 inhibitors. Research on novel therapeutics is well-summarised in this review, with techniques such as CRISPR-Cas9, peptide nucleic acids, and antimicrobial peptides, which eliminate mor genes within the host. Other novel therapeutics were identified by reviving old FDA-approved drugs. Some were effective against $m c r$-producing isolates or were synergistic with colistin. 
medRxiv preprint doi: https://doi.org/10.1101/2022.02.28.22271560; this version posted March 1, 2022. The copyright holder for this preprint (which was not certified by peer review) is the author/funder, who has granted medRxiv a license to display the preprint in perpetuity.

It is made available under a CC-BY-NC-ND 4.0 International license .

1284 These therapeutics, however, need to be further evaluated for their toxicity in humans. This

1285 will aid in alleviating the threat imposed by MCRPE in the public health sector

1286 Funding: This work was funded by a grant from the National Health Laboratory Service

1287 (NHLS) given to Dr. John Osei Sekyere under grant number GRANT004 94809 (reference

1288 number PR2010486).

1289 Acknowledgements: None

1290 Transparency declaration: None

1291

1292

1293

1294

1295

1296

1297

1298

1299

1300

1301

1302

1303

1304

1305

1306

1307

1308

1309

1310

1311

1312

1313

1314

1315

1316

1317

1318

1319

1320

1321

1322

1323

1324

1325

\section{$\underline{\text { References }}$}

1. Falagas, M.E., Kasiakou, S.K. \& Saravolatz, L.D. Colistin: the revival of polymyxins for the management of multidrug-resistant gram-negative bacterial infections. Clinical infectious diseases 40, 1333-1341 (2005).

2. Nigam, A., Kumari, A., Jain, R. \& Batra, S. Colistin neurotoxicity: revisited. Case Reports 2015, bcr2015210787 (2015).

3. Ye, H. et al. Diversified mcr-1-harbouring plasmid reservoirs confer resistance to colistin in human gut microbiota. MBio 7, e00177-00116 (2016).

4. Al Atya, A.K. et al. Effects of colistin and bacteriocins combinations on the in vitro growth of Escherichia coli strains from swine origin. Probiotics and antimicrobial proteins 8, 183-190 (2016).

5. (!!! INVALID CITATION !!! (Bulman et al., 2017)).

6. Fyfe, C. et al. Eravacycline is active against bacterial isolates expressing the polymyxin resistance gene mcr-1. Antimicrobial agents and chemotherapy 60, 6989-6990 (2016).

7. Paterson, D.L. \& Harris, P.N. Colistin resistance: a major breach in our last line of defence. The Lancet. Infectious diseases 16, 132-133 (2016).

8. Gunn, J.S. The Salmonella PmrAB regulon: lipopolysaccharide modifications, antimicrobial peptide resistance and more. Trends in microbiology 16, 284-290 (2008).

9. Cannatelli, A. et al. In vivo emergence of colistin resistance in Klebsiella pneumoniae producing KPC-type carbapenemases mediated by insertional inactivation of the PhoQ/PhoP mgrB regulator. Antimicrobial agents and chemotherapy 57, 5521-5526 (2013).

10. Mmatli, M., Mbelle, N.M., Maningi, N.E. \& Osei Sekyere, J. Emerging Transcriptional and Genomic Mechanisms Mediating Carbapenem and Polymyxin Resistance in Enterobacteriaceae: a Systematic Review of Current Reports. Msystems 5, e00783-00720 (2020).

11. Liu, Y.Y. et al. Emergence of plasmid-mediated colistin resistance mechanism MCR-1 in animals and human beings in China: a microbiological and molecular biological study. Lancet Infect Dis 16, 161-168 (2016).

12. Hu, Y., Liu, F., Lin, I.Y., Gao, G.F. \& Zhu, B. Dissemination of the mcr-1 colistin resistance gene. Lancet Infect Dis 16, 146-147 (2016).

13. Hu, M. et al. Crystal Structure of Escherichia coli originated MCR-1, a phosphoethanolamine transferase for Colistin Resistance. Sci Rep 6, 38793 (2016).

14. Fage, C.D., Brown, D.B., Boll, J.M., Keatinge-Clay, A.T. \& Trent, M.S. Crystallographic study of the phosphoethanolamine transferase EptC required for polymyxin resistance and motility in 
medRxiv preprint doi: https://doi.org/10.1101/2022.02.28.22271560; this version posted March 1, 2022. The copyright holder for this preprint (which was not certified by peer review) is the author/funder, who has granted medRxiv a license to display the preprint in perpetuity.

It is made available under a CC-BY-NC-ND 4.0 International license .

1326

1327

1328

1329

1330

1331

1332

1333

1334

1335

1336

1337

1338

1339

1340

1341

1342

1343

1344

1345

1346

1347

1348

1349

1350

1351

1352

1353

1354

1355

1356

1357

1358

1359

1360

1361

1362

1363

1364

1365

1366

1367

1368

1369

1370

1371

1372

1373

1374

1375

1376
Campylobacter jejuni. Acta crystallographica. Section D, Biological crystallography 70, 27302739 (2014).

15. Wanty, C. et al. The structure of the neisserial lipooligosaccharide phosphoethanolamine transferase A (LptA) required for resistance to polymyxin. Journal of molecular biology 425, 3389-3402 (2013).

16. $\mathrm{Xu}, \mathrm{Y}$. et al. An Evolutionarily Conserved Mechanism for Intrinsic and Transferable Polymyxin Resistance. mBio 9 (2018).

17. Rebelo, A.R. et al. Multiplex PCR for detection of plasmid-mediated colistin resistance determinants, mcr-1, mcr-2, mcr-3, mcr- 4 and $\mathrm{mcr}-5$ for surveillance purposes. Euro Surveill 23 (2018).

18. Roer, L. et al. Novel mcr-3 variant, encoding mobile colistin resistance, in an ST131 Escherichia coli isolate from bloodstream infection, Denmark, 2014. Euro Surveill 22 (2017).

19. Yang, Y.Q. et al. Colistin Resistance Gene mcr-1 and Its Variant in Escherichia coli Isolates from Chickens in China. Antimicrob Agents Chemother 61 (2017).

20. Xavier, B.B. et al. Identification of a novel plasmid-mediated colistin-resistance gene, mcr-2, in Escherichia coli, Belgium, June 2016. Euro Surveill 21 (2016).

21. Wang, Y. et al. Changes in colistin resistance and mcr-1 abundance in Escherichia coli of animal and human origins following the ban of colistin-positive additives in China: an epidemiological comparative study. Lancet Infect Dis 20, 1161-1171 (2020).

22. Di Pilato, V. et al. mcr-1.2, a New mcr Variant Carried on a Transferable Plasmid from a Colistin-Resistant KPC Carbapenemase-Producing Klebsiella pneumoniae Strain of Sequence Type 512. Antimicrob Agents Chemother 60, 5612-5615 (2016).

23. Anjum, M.F. et al. Colistin resistance in Salmonella and Escherichia coli isolates from a pig farm in Great Britain. J Antimicrob Chemother 71, 2306-2313 (2016).

24. Hsu, L.Y. et al. Carbapenem-Resistant Acinetobacter baumannii and Enterobacteriaceae in South and Southeast Asia. Clin Microbiol Rev 30, 1-22 (2017).

25. Snyman, Y. et al. Characterisation of mcr-4.3 in a colistin-resistant Acinetobacter nosocomialis clinical isolate from Cape Town, South Africa. J Glob Antimicrob Resist 25, 102106 (2021).

26. Snesrud, E. et al. Chromosomally Encoded mcr-5 in Colistin-Nonsusceptible Pseudomonas aeruginosa. Antimicrob Agents Chemother 62 (2018).

27. Kempf, I., Jouy, E. \& Chauvin, C. Colistin use and colistin resistance in bacteria from animals. Int J Antimicrob Agents 48, 598-606 (2016).

28. Monte, D.F. et al. Chicken Meat as a Reservoir of Colistin-Resistant Escherichia coli Strains Carrying mcr-1 Genes in South America. Antimicrob Agents Chemother 61 (2017).

29. Runcharoen, C. et al. Whole genome sequencing of ESBL-producing Escherichia coli isolated from patients, farm waste and canals in Thailand. Genome Med 9, 81 (2017).

30. WHO (2011).

31. Collignon, P.C. et al. World Health Organization ranking of antimicrobials according to their importance in human medicine: a critical step for developing risk management strategies to control antimicrobial resistance from food animal production. Clinical Infectious Diseases 63, 1087-1093 (2016).

32. Sun, J. et al. Co-occurrence of mcr-1 in the chromosome and on an IncHI2 plasmid: persistence of colistin resistance in Escherichia coli. Int J Antimicrob Agents 51, 842-847 (2018).

33. Sun, J. et al. Deciphering MCR-2 Colistin Resistance. mBio 8 (2017).

34. Gomi, R. et al. Molecular Characterization of a Multidrug-Resistant IncF Plasmid Carrying mcr-3.1 in an Escherichia coli Sequence Type 393 Strain of Wastewater Origin. Int J Antimicrob Agents 54, 524-526 (2019).

35. Wang, Z., Fu, Y., Du, X.D., Jiang, H. \& Wang, Y. Potential transferability of mcr-3 via IS26mediated homologous recombination in Escherichia coli. Emerg Microbes Infect 7, 55 (2018). 
medRxiv preprint doi: https://doi.org/10.1101/2022.02.28.22271560; this version posted March 1, 2022. The copyright holder for this preprint (which was not certified by peer review) is the author/funder, who has granted medRxiv a license to display the preprint in perpetuity.

It is made available under a CC-BY-NC-ND 4.0 International license .

1377

1378

1379

1380

1381

1382

1383

1384

1385

1386

1387

1388

1389

1390

1391

1392

1393

1394

1395

1396

1397

1398

1399

1400

1401

1402

1403

1404

1405

1406

1407

1408

1409

1410

1411

1412

1413

1414

1415

1416

1417

1418

1419

1420

1421

1422

1423

1424

1425
36. Poirel, L. et al. Genetic Features of MCR-1-Producing Colistin-Resistant Escherichia coli Isolates in South Africa. Antimicrob Agents Chemother 60, 4394-4397 (2016).

37. Poirel, L., Kieffer, N. \& Nordmann, P. In vitro study of ISApl1-mediated mobilization of the colistin resistance gene mcr-1. Antimicrobial agents and chemotherapy 61 (2017).

38. Kieffer, N., Nordmann, P. \& Poirel, L. Moraxella Species as Potential Sources of MCR-Like Polymyxin Resistance Determinants. Antimicrob Agents Chemother 61 (2017).

39. Poirel, L. et al. MCR-2-mediated plasmid-borne polymyxin resistance most likely originates from Moraxella pluranimalium. J Antimicrob Chemother 72, 2947-2949 (2017).

40. Snesrud, E., McGann, P. \& Chandler, M. The Birth and Demise of the ISApl1-mcr-1-ISApl1 Composite Transposon: the Vehicle for Transferable Colistin Resistance. mBio 9, e0238102317 (2018).

41. Li, R. et al. Genetic basis of chromosomally-encoded mcr-1 gene. Int J Antimicrob Agents 51, 578-585 (2018).

42. AbuOun, M. et al. mcr-1 and mcr-2 variant genes identified in Moraxella species isolated from pigs in Great Britain from 2014 to 2015. J Antimicrob Chemother 72, 2745-2749 (2017).

43. Stoesser, N., Mathers, A.J., Moore, C.E., Day, N.P. \& Crook, D.W. Colistin resistance gene mcr-1 and pHNSHP45 plasmid in human isolates of Escherichia coli and Klebsiella pneumoniae. Lancet Infect Dis 16, 285-286 (2016).

44. Snesrud, E. et al. A Model for Transposition of the Colistin Resistance Gene mcr-1 by ISApl1. Antimicrob Agents Chemother 60, 6973-6976 (2016).

45. Zurfluh, K., Tasara, T., Poirel, L., Nordmann, P. \& Stephan, R. Draft Genome Sequence of Escherichia coli S51, a Chicken Isolate Harboring a Chromosomally Encoded mcr-1 Gene. Genome Announc 4 (2016).

46. Tegetmeyer, H.E., Jones, S.C., Langford, P.R. \& Baltes, N. ISApl1, a novel insertion element of Actinobacillus pleuropneumoniae, prevents ApxIV-based serological detection of serotype 7 strain AP76. Veterinary microbiology 128, 342-353 (2008).

47. Szabó, M., Kiss, J., Nagy, Z., Chandler, M. \& Olasz, F. Sub-terminal sequences modulating IS30 transposition in vivo and in vitro. Journal of molecular biology 375, 337-352 (2008).

48. Wang, Q. et al. Phenotypic and Genotypic Characterization of Carbapenem-resistant Enterobacteriaceae: Data From a Longitudinal Large-scale CRE Study in China (2012-2016). Clin Infect Dis 67, S196-s205 (2018).

49. Snesrud, E. et al. Analysis of Serial Isolates of mcr-1-Positive Escherichia coli Reveals a Highly Active ISApl1 Transposon. Antimicrob Agents Chemother 61 (2017).

50. Zhao, F., Feng, Y., Lü, X., McNally, A. \& Zong, Z. IncP Plasmid Carrying Colistin Resistance Gene mcr-1 in Klebsiella pneumoniae from Hospital Sewage. Antimicrob Agents Chemother 61 (2017).

51. Petrillo, M., Angers-Loustau, A. \& Kreysa, J. Possible genetic events producing colistin resistance gene mcr-1. Lancet Infect Dis 16, 280 (2016).

52. Sia, C.M. et al. The characterization of mobile colistin resistance (mcr) genes among 332000 Salmonella enterica genomes from routine public health surveillance in England. Microb Genom 6 (2020).

53. Li, R., Chen, K., Chan, E.W. \& Chen, S. Characterization of the stability and dynamics of Tn6330 in an Escherichia coli strain by nanopore long reads. J Antimicrob Chemother 74, 1807-1811 (2019).

54. Tarabai, H. et al. Plasmid-Mediated mcr-1 Colistin Resistance in Escherichia coli from a Black Kite in Russia. Antimicrob Agents Chemother 63 (2019).

55. Ji, X. et al. Dissemination of extended-spectrum $\beta$-lactamase-producing Escherichia coli carrying mcr-1 among multiple environmental sources in rural China and associated risk to human health. Environ Pollut 251, 619-627 (2019). 
medRxiv preprint doi: https://doi.org/10.1101/2022.02.28.22271560; this version posted March 1, 2022. The copyright holder for this preprint (which was not certified by peer review) is the author/funder, who has granted medRxiv a license to display the preprint in perpetuity.

It is made available under a CC-BY-NC-ND 4.0 International license .

1426

1427

1428

1429

1430

1431

1432

1433

1434

1435

1436

1437

1438

1439

1440

1441

1442

1443

1444

1445

1446

1447

1448

1449

1450

1451

1452

1453

1454

1455

1456

1457

1458

1459

1460

1461

1462

1463

1464

1465

1466

1467

1468

1469

1470

1471

1472

1473

1474

1475
56. Tijet, N. et al. Molecular characteristics of mcr-1-carrying plasmids and new mcr-1 variant recovered from polyclonal clinical Escherichia coli from Argentina and Canada. PLoS One 12, e0180347 (2017).

57. Sun, J. et al. Genetic Analysis of the IncX4 Plasmids: Implications for a Unique Pattern in the mcr-1 Acquisition. Sci Rep 7, 424 (2017).

58. Nang, S.C. et al. Fitness cost of mcr-1-mediated polymyxin resistance in Klebsiella pneumoniae. J Antimicrob Chemother 73, 1604-1610 (2018).

59. Li, R. et al. Genetic characterization of mcr-1-bearing plasmids to depict molecular mechanisms underlying dissemination of the colistin resistance determinant. J Antimicrob Chemother 72, 393-401 (2017).

60. He, T. et al. Characterization of NDM-5-positive extensively resistant Escherichia coli isolates from dairy cows. Vet Microbiol 207, 153-158 (2017).

61. Andersson, D.I. The biological cost of mutational antibiotic resistance: any practical conclusions? Current opinion in microbiology 9, 461-465 (2006).

62. Cannatelli, A., Santos-Lopez, A., Giani, T., Gonzalez-Zorn, B. \& Rossolini, G.M. Polymyxin resistance caused by $\mathrm{mgrB}$ inactivation is not associated with significant biological cost in Klebsiella pneumoniae. Antimicrobial agents and chemotherapy 59, 2898-2900 (2015).

63. Giordano, C. et al. Reduced Fitness Costs of mcr-1.2 Compared to Mutated pmrB in Isogenic Colistin-Resistant KPC-3-Producing Klebsiella pneumoniae. mSphere 4 (2019).

64. Phan, M.-D. et al. Modifications in the pmrB gene are the primary mechanism for the development of chromosomally encoded resistance to polymyxins in uropathogenic Escherichia coli. Journal of Antimicrobial Chemotherapy 72, 2729-2736 (2017).

65. Cannatelli, A. et al. An allelic variant of the PmrB sensor kinase responsible for colistin resistance in an Escherichia coli strain of clinical origin. Sci Rep 7, 5071 (2017).

66. Cheng, Y.-H., Lin, T.-L., Lin, Y.-T. \& Wang, J.-T. Amino acid substitutions of CrrB responsible for resistance to colistin through $\mathrm{CrrC}$ in Klebsiella pneumoniae. Antimicrobial agents and chemotherapy 60, 3709-3716 (2016).

67. Tietgen, M. et al. Impact of the colistin resistance gene mor-1 on bacterial fitness. Int $J$ Antimicrob Agents 51, 554-561 (2018).

68. Wang, R. et al. The prevalence of colistin resistance in Escherichia coli and Klebsiella pneumoniae isolated from food animals in China: coexistence of mcr-1 and bla(NDM) with low fitness cost. Int J Antimicrob Agents 51, 739-744 (2018).

69. Zheng, B. et al. Complete genome sequencing and genomic characterization of two Escherichia coli strains co-producing MCR-1 and NDM-1 from bloodstream infection. Sci Rep 7, 17885 (2017).

70. Yang, Q. et al. Balancing mcr-1 expression and bacterial survival is a delicate equilibrium between essential cellular defence mechanisms. Nat Commun 8, 2054 (2017).

71. Ma, K., Feng, Y. \& Zong, Z. Fitness cost of a mcr-1-carrying IncHI2 plasmid. PLoS One 13, e0209706 (2018).

72. Dahlberg, C. \& Chao, L. Amelioration of the cost of conjugative plasmid carriage in Eschericha coli K12. Genetics 165, 1641-1649 (2003).

73. Zhang, Y. et al. Decreased Fitness and Virulence in ST10 Escherichia coli Harboring bla(NDM5) and mcr-1 against a ST4981 Strain with bla(NDM-5). Front Cell Infect Microbiol 7, 242 (2017).

74. Arcilla, M.S. et al. Dissemination of the mcr-1 colistin resistance gene. Lancet Infect Dis 16, 147-149 (2016).

75. Wei, P. et al. Substrate analog interaction with MCR-1 offers insight into the rising threat of the plasmid-mediated transferable colistin resistance. Faseb j 32, 1085-1098 (2018).

76. Liu, Z.-X., Han, Z., Yu, X.-L., Wen, G. \& Zeng, C. Crystal structure of the catalytic domain of MCR-1 (cMCR-1) in complex with d-Xylose. Crystals 8, 172 (2018). 
medRxiv preprint doi: https://doi.org/10.1101/2022.02.28.22271560; this version posted March 1, 2022. The copyright holder for this preprint (which was not certified by peer review) is the author/funder, who has granted medRxiv a license to display the preprint in perpetuity.

It is made available under a CC-BY-NC-ND 4.0 International license .

1476

1477

1478

1479

1480

1481

1482

1483

1484

1485

1486

1487

1488

1489

1490

1491

1492

1493

1494

1495

1496

1497

1498

1499

1500

1501

1502

1503

1504

1505

1506

1507

1508

1509

1510

1511

1512

1513

1514

1515

1516

1517

1518

1519

1520

1521

1522

1523

1524
77. Stojanoski, V. et al. Structure of the catalytic domain of the colistin resistance enzyme MCR1. BMC Biol 14, 81 (2016).

78. Hinchliffe, P. et al. Insights into the Mechanistic Basis of Plasmid-Mediated Colistin Resistance from Crystal Structures of the Catalytic Domain of MCR-1. Sci Rep 7, 39392 (2017).

79. Gao, R. et al. Dissemination and mechanism for the MCR-1 colistin resistance. PLoS pathogens 12, e1005957 (2016).

80. Anandan, A. et al. Structure of a lipid A phosphoethanolamine transferase suggests how conformational changes govern substrate binding. Proceedings of the National Academy of Sciences 114, 2218-2223 (2017).

81. Xu, Y., Lin, J., Cui, T., Srinivas, S. \& Feng, Y. Mechanistic insights into transferable polymyxin resistance among gut bacteria. J Biol Chem 293, 4350-4365 (2018).

82. Dortet, L. et al. Rapid detection and discrimination of chromosome- and MCR-plasmidmediated resistance to polymyxins by MALDI-TOF MS in Escherichia coli: the MALDIxin test. J Antimicrob Chemother 73, 3359-3367 (2018).

83. Wanty, C. et al. The structure of the neisserial lipooligosaccharide phosphoethanolamine transferase A (LptA) required for resistance to polymyxin. J Mol Biol 425, 3389-3402 (2013).

84. Partridge, S.R. mcr-2 in the IncX4 plasmid pKP37-BE is flanked by directly oriented copies of ISEc69. J Antimicrob Chemother 72, 1533-1535 (2017).

85. Garcia-Graells, C. et al. Detection of Plasmid-Mediated Colistin Resistance, mcr-1 and mcr-2 Genes, in Salmonella spp. Isolated from Food at Retail in Belgium from 2012 to 2015. Foodborne Pathog Dis 15, 114-117 (2018).

86. Zhang, J. et al. Molecular detection of colistin resistance genes (mcr-1, mcr-2 and $\mathrm{mcr}-3$ ) in nasal/oropharyngeal and anal/cloacal swabs from pigs and poultry. Sci Rep 8, 3705 (2018).

87. Ghasemian, A. et al. Expression of adhesin genes and biofilm formation among Klebsiella oxytoca clinical isolates from patients with antibiotic-associated haemorrhagic colitis. J Med Microbiol 68, 978-985 (2019).

88. Ahmed, Z.S., Elshafiee, E.A., Khalefa, H.S., Kadry, M. \& Hamza, D.A. Evidence of colistin resistance genes (mcr-1 and $\mathrm{mcr}-2$ ) in wild birds and its public health implication in Egypt. Antimicrob Resist Infect Control 8, 197 (2019).

89. Partridge, S.R. et al. Proposal for assignment of allele numbers for mobile colistin resistance (mcr) genes. J Antimicrob Chemother 73, 2625-2630 (2018).

90. Yin, W. et al. Novel Plasmid-Mediated Colistin Resistance Gene mcr-3 in Escherichia coli. mBio 8 (2017).

91. Kieffer, N. et al. Genetic and Functional Characterization of an MCR-3-Like EnzymeProducing Escherichia coli Isolate Recovered from Swine in Brazil. Antimicrob Agents Chemother 62 (2018).

92. Wang, X. et al. Presence of an mcr-3 Variant in Aeromonas caviae, Proteus mirabilis, and Escherichia coli from One Domestic Duck. Antimicrob Agents Chemother 62 (2018).

93. Long, $\mathrm{H}$. et al. The co-transfer of plasmid-borne colistin-resistant genes mcr-1 and mcr-3.5, the carbapenemase gene bla(NDM-5) and the $16 \mathrm{~S}$ methylase gene rmtB from Escherichia coli. Sci Rep 9, 696 (2019).

94. Yang, Q.E. et al. Compensatory mutations modulate the competitiveness and dynamics of plasmid-mediated colistin resistance in Escherichia coli clones. Isme j 14, 861-865 (2020).

95. Liu, L., Feng, Y., Zhang, X., McNally, A. \& Zong, Z. New Variant of mcr-3 in an Extensively Drug-Resistant Escherichia coli Clinical Isolate Carrying mcr-1 and bla(NDM-5). Antimicrob Agents Chemother 61 (2017).

96. Creighton, J. et al. Co-occurrence of mcr-1 and mcr-3 genes in a single Escherichia coli in New Zealand. J Antimicrob Chemother 74, 3113-3116 (2019). 
medRxiv preprint doi: https://doi.org/10.1101/2022.02.28.22271560; this version posted March 1, 2022. The copyright holder for this preprint (which was not certified by peer review) is the author/funder, who has granted medRxiv a license to display the preprint in perpetuity.

It is made available under a CC-BY-NC-ND 4.0 International license .

1525

1526

1527

1528

1529

1530

1531

1532

1533

1534

1535

1536

1537

1538

1539

1540

1541

1542

1543

1544

1545

1546

1547

1548

1549

1550

1551

1552

1553

1554

1555

1556

1557

1558

1559

1560

1561

1562

1563

1564

1565

1566

1567

1568

1569

1570

1571

1572

1573
97. Xiang, R. et al. Colocation of the Polymyxin Resistance Gene mcr-1 and a Variant of mcr-3 on a Plasmid in an Escherichia coli Isolate from a Chicken Farm. Antimicrob Agents Chemother 62 (2018).

98. Cabello, F.C., Tomova, A., Ivanova, L. \& Godfrey, H.P. Aquaculture and mcr colistin resistance determinants. MBio 8, e01229-01217 (2017).

99. Wang, Z. et al. Genetic environment of colistin resistance genes mcr-1 and mcr-3 in Escherichia coli from one pig farm in China. Vet Microbiol 230, 56-61 (2019).

100. Litrup, E. et al. Plasmid-borne colistin resistance gene mcr-3 in Salmonella isolates from human infections, Denmark, 2009-17. Euro Surveill 22 (2017).

101. Carattoli, A. et al. Novel plasmid-mediated colistin resistance mcr-4 gene in Salmonella and Escherichia coli, Italy 2013, Spain and Belgium, 2015 to 2016. Euro Surveill 22 (2017).

102. Chavda, B. et al. Coidentification of mcr-4.3 and bla(NDM-1) in a Clinical Enterobacter cloacae Isolate from China. Antimicrob Agents Chemother 62 (2018).

103. Carattoli, A., Carretto, E., Brovarone, F., Sarti, M. \& Villa, L. Comparative analysis of an mcr-4 Salmonella enterica subsp. enterica monophasic variant of human and animal origin. J Antimicrob Chemother 73, 3332-3335 (2018).

104. García, V. et al. Co-occurrence of mcr-1, mcr-4 and mcr-5 genes in multidrug-resistant ST10 Enterotoxigenic and Shiga toxin-producing Escherichia coli in Spain (2006-2017). Int J Antimicrob Agents 52, 104-108 (2018).

105. Teo, J.W.P. et al. mcr-3 and mcr-4 Variants in Carbapenemase-Producing Clinical Enterobacteriaceae Do Not Confer Phenotypic Polymyxin Resistance. J Clin Microbiol 56 (2018).

106. Sun, Q. et al. Leclercia adecarboxylata From Human Gut Flora Carries mcr-4.3 and bla (IMP4)-Bearing Plasmids. Front Microbiol 10, 2805 (2019).

107. Borowiak, M. et al. Identification of a novel transposon-associated phosphoethanolamine transferase gene, mcr-5, conferring colistin resistance in d-tartrate fermenting Salmonella enterica subsp. enterica serovar Paratyphi B. J Antimicrob Chemother 72, 3317-3324 (2017).

108. Fleres, G. et al. Detection of a novel mcr-5.4 gene variant in hospital tap water by shotgun metagenomic sequencing. J Antimicrob Chemother 74, 3626-3628 (2019).

109. Guo, S. et al. Conjugative IncX1 Plasmid Harboring Colistin Resistance Gene mcr-5.1 in Escherichia coli Isolated from Chicken Rice Retailed in Singapore. Antimicrob Agents Chemother 63 (2019).

110. Borowiak, M. et al. Characterization of mcr-5-Harboring Salmonella enterica subsp. enterica Serovar Typhimurium Isolates from Animal and Food Origin in Germany. Antimicrob Agents Chemother 63 (2019).

111. Kieffer, N., Nordmann, P., Millemann, Y. \& Poirel, L. Functional Characterization of a Miniature Inverted Transposable Element at the Origin of mcr-5 Gene Acquisition in Escherichia coli. Antimicrob Agents Chemother 63 (2019).

112. Hammerl, J.A. et al. mcr-5 and a novel mcr-5.2 variant in Escherichia coli isolates from food and food-producing animals, Germany, 2010 to 2017. J Antimicrob Chemother 73, 1433-1435 (2018).

113. Ma, S. et al. Mobile colistin resistance gene $\mathrm{mcr}-5$ in porcine Aeromonas hydrophila. J Antimicrob Chemother 73, 1777-1780 (2018).

114. Yang, Y.Q., Li, Y.X., Lei, C.W., Zhang, A.Y. \& Wang, H.N. Novel plasmid-mediated colistin resistance gene mcr-7.1 in Klebsiella pneumoniae. J Antimicrob Chemother 73, 1791-1795 (2018).

115. Furlan, J.P.R. et al. Occurrence of clinically relevant antimicrobial resistance genes, including mcr-3 and mcr-7.1, in soil and water from a recreation club. International Journal of Environmental Health Research, 1-10 (2020). 
medRxiv preprint doi: https://doi.org/10.1101/2022.02.28.22271560; this version posted March 1, 2022. The copyright holder for this preprint (which was not certified by peer review) is the author/funder, who has granted medRxiv a license to display the preprint in perpetuity.

It is made available under a CC-BY-NC-ND 4.0 International license .

1574

1575

1576

1577

1578

1579

1580

1581

1582

1583

1584

1585

1586

1587

1588

1589

1590

1591

1592

1593

1594

1595

1596

1597

1598

1599

1600

1601

1602

1603

1604

1605

1606

1607

1608

1609

1610

1611

1612

1613

1614

1615

1616

1617

1618

1619

1620

1621

1622

1623
116. Furlan, J.P.R. et al. Occurrence and abundance of clinically relevant antimicrobial resistance genes in environmental samples after the Brumadinho dam disaster, Brazil. Science of The Total Environment 726, 138100 (2020).

117. Dos Santos, L.D.R. et al. Co-occurrence of mcr-1, mcr-3, $\mathrm{mcr}-7$ and clinically relevant antimicrobial resistance genes in environmental and fecal samples. Archives of microbiology 202, 1795-1800 (2020).

118. Wang, X. et al. Emergence of a novel mobile colistin resistance gene, mcr-8, in NDMproducing Klebsiella pneumoniae. Emerg Microbes Infect 7, 122 (2018).

119. Wang, X. et al. Emergence of Colistin Resistance Gene mcr-8 and Its Variant in Raoultella ornithinolytica. Front Microbiol 10, 228 (2019).

120. Bonnin, R.A., Bernabeu, S., Jaureguy, F., Naas, T. \& Dortet, L. MCR-8 mediated colistin resistance in a carbapenem-resistant Klebsiella pneumoniae isolated from a repatriated patient from Morocco. Int J Antimicrob Agents 55, 105920 (2020).

121. Wu, B. et al. Heterogeneity and Diversity of mcr-8 Genetic Context in Chicken-Associated Klebsiella pneumoniae. Antimicrob Agents Chemother 65 (2020).

122. Yang, X., Liu, L., Wang, Z., Bai, L. \& Li, R. Emergence of mcr-8.2-bearing Klebsiella quasipneumoniae of animal origin. J Antimicrob Chemother 74, 2814-2817 (2019).

123. Sun, S. et al. Co-existence of a novel plasmid-mediated efflux pump with colistin resistance gene mcr in one plasmid confers transferable multidrug resistance in Klebsiella pneumoniae. Emerg Microbes Infect 9, 1102-1113 (2020).

124. Salloum, T. et al. First report of plasmid-mediated colistin resistance mcr-8.1 gene from a clinical Klebsiella pneumoniae isolate from Lebanon. Antimicrob Resist Infect Control 9, 94 (2020).

125. Ngbede, E.O. et al. Identification of mobile colistin resistance genes (mcr-1.1, $\mathrm{mcr}-5$ and $\mathrm{mcr}-$ 8.1) in Enterobacteriaceae and Alcaligenes faecalis of human and animal origin, Nigeria. Int J Antimicrob Agents 56, 106108 (2020).

126. Nabti, L.Z. et al. Development of real-time PCR assay allowed describing the first clinical Klebsiella pneumoniae isolate harboring plasmid-mediated colistin resistance mcr- 8 gene in Algeria. J Glob Antimicrob Resist 20, 266-271 (2020).

127. Carroll, L.M. et al. Identification of Novel Mobilized Colistin Resistance Gene mcr-9 in a Multidrug-Resistant, Colistin-Susceptible Salmonella enterica Serotype Typhimurium Isolate. mBio 10 (2019).

128. Börjesson, S. et al. A link between the newly described colistin resistance gene mcr-9 and clinical Enterobacteriaceae isolates carrying bla(SHV-12) from horses in Sweden. J Glob Antimicrob Resist 20, 285-289 (2020).

129. Chavda, K.D. et al. First Report of bla (VIM-4)- and mcr-9-Coharboring Enterobacter Species Isolated from a Pediatric Patient. mSphere 4 (2019).

130. Kananizadeh, P. et al. Emergence of carbapenem-resistant and colistin-susceptible Enterobacter cloacae complex co-harboring bla(IMP-1) and mcr-9 in Japan. BMC Infect Dis 20, 282 (2020).

131. Osei Sekyere, J., Maningi, N.E., Modipane, L. \& Mbelle, N.M. Emergence of mcr-9.1 in Extended-Spectrum- $\beta$-Lactamase-Producing Clinical Enterobacteriaceae in Pretoria, South Africa: Global Evolutionary Phylogenomics, Resistome, and Mobilome. mSystems 5 (2020).

132. Ding, M. et al. Co-infections of two carbapenemase-producing Enterobacter hormaechei clinical strains isolated from the same diabetes individual in China. J Med Microbiol 70 (2021).

133. Lin, M. et al. Co-Occurrence of mcr-9 and bla (NDM-1) in Enterobacter cloacae Isolated from a Patient with Bloodstream Infection. Infect Drug Resist 13, 1397-1402 (2020).

134. Ribeiro, T.G. et al. Citrobacter telavivum sp. nov. with chromosomal mcr-9 from hospitalized patients. Eur J Clin Microbiol Infect Dis 40, 123-131 (2021). 
medRxiv preprint doi: https://doi.org/10.1101/2022.02.28.22271560; this version posted March 1, 2022. The copyright holder for this preprint (which was not certified by peer review) is the author/funder, who has granted medRxiv a license to display the preprint in perpetuity.

It is made available under a CC-BY-NC-ND 4.0 International license .

1624

1625

1626

1627

1628

1629

1630

1631

1632

1633

1634

1635

1636

1637

1638

1639

1640

1641

1642

1643

1644

1645

1646

1647

1648

1649

1650

1651

1652

1653

1654

1655

1656

1657

1658

1659

1660

1661

1662

1663

1664

1665

1666

1667

1668

1669

1670

1671

1672

1673
135. Yuan, Y. et al. Coproduction Of MCR-9 And NDM-1 By Colistin-Resistant Enterobacter hormaechei Isolated From Bloodstream Infection. Infect Drug Resist 12, 2979-2985 (2019).

136. Khanawapee, A. et al. Distribution and Molecular Characterization of Escherichia coli Harboring mcr Genes Isolated from Slaughtered Pigs in Thailand. Microb Drug Resist 27, 971979 (2021).

137. Cha, M.H. et al. Emergence of Transferable mcr-9 Gene-Carrying Colistin-Resistant Salmonella enterica Dessau ST14 Isolated from Retail Chicken Meat in Korea. Foodborne Pathog Dis 17, 720-727 (2020).

138. Tyson, G.H. et al. The mcr-9 Gene of Salmonella and Escherichia coli Is Not Associated with Colistin Resistance in the United States. Antimicrob Agents Chemother 64 (2020).

139. Li, Y. et al. Characterization of the global distribution and diversified plasmid reservoirs of the colistin resistance gene mcr-9. Sci Rep 10, 8113 (2020).

140. Kieffer, N. et al. mcr-9, an Inducible Gene Encoding an Acquired Phosphoethanolamine Transferase in Escherichia coli, and Its Origin. Antimicrob Agents Chemother 63 (2019).

141. Wang, C. et al. Identification of novel mobile colistin resistance gene mcr-10. Emerg Microbes Infect 9, 508-516 (2020).

142. Xu, T. et al. Identification of mcr-10 carried by self-transmissible plasmids and chromosome in Enterobacter roggenkampii strains isolated from hospital sewage water. Environ Pollut 268, 115706 (2021).

143. Yang, J. et al. Potential Mobilization of mcr-10 by an Integrative Mobile Element via SiteSpecific Recombination in Cronobacter sakazakii. Antimicrob Agents Chemother 65 (2021).

144. Sato, T. et al. Complete Genome Sequence of an mcr-10-Possessing Enterobacter roggenkampii Strain Isolated from a Dog in Japan. Microbiology Resource Announcements 10, e00426-00421 (2021).

145. Lei, C.W., Zhang, Y., Wang, Y.T. \& Wang, H.N. Detection of Mobile Colistin Resistance Gene mcr-10.1 in a Conjugative Plasmid from Enterobacter roggenkampii of Chicken Origin in China. Antimicrob Agents Chemother 64 (2020).

146. Nguyen, N.T. et al. Use of Colistin and Other Critical Antimicrobials on Pig and Chicken Farms in Southern Vietnam and Its Association with Resistance in Commensal Escherichia coli Bacteria. Appl Environ Microbiol 82, 3727-3735 (2016).

147. Carrique-Mas, J.J. et al. Antimicrobial usage in chicken production in the Mekong Delta of Vietnam. Zoonoses and public health 62, 70-78 (2015).

148. Monte, D.F. et al. Chicken meat as a reservoir of colistin-resistant Escherichia coli strains carrying mcr-1 genes in South America. Antimicrobial agents and chemotherapy 61 (2017).

149. Clemente, L. et al. Revealing mcr-1-positive ESBL-producing Escherichia coli strains among Enterobacteriaceae from food-producing animals (bovine, swine and poultry) and meat (bovine and swine), Portugal, 2010-2015. Int J Food Microbiol 296, 37-42 (2019).

150. Shen, Y. et al. Anthropogenic and environmental factors associated with high incidence of mcr-1 carriage in humans across China. Nat Microbiol 3, 1054-1062 (2018).

151. Trung, N.V. et al. Zoonotic Transmission of mcr-1 Colistin Resistance Gene from Small-Scale Poultry Farms, Vietnam. Emerg Infect Dis 23, 529-532 (2017).

152. Hille, K. et al. Investigation of potential risk factors for the occurrence of Escherichia coli isolates from German fattening pig farms harbouring the mcr-1 colistin-resistance gene. Int J Antimicrob Agents 51, 177-180 (2018).

153. Xia, X. et al. Association of colistin residues and manure treatment with the abundance of mcr-1 gene in swine feedlots. Environ Int 127, 361-370 (2019).

154. Luo, J. et al. Emergence of mcr-1 in Raoultella ornithinolytica and Escherichia coli Isolates from Retail Vegetables in China. Antimicrob Agents Chemother 61 (2017).

155. Shen, Y. et al. Integrated aquaculture contributes to the transfer of mcr-1 between animals and humans via the aquaculture supply chain. Environ Int 130, 104708 (2019). 
medRxiv preprint doi: https://doi.org/10.1101/2022.02.28.22271560; this version posted March 1, 2022. The copyright holder for this preprint (which was not certified by peer review) is the author/funder, who has granted medRxiv a license to display the preprint in perpetuity.

It is made available under a CC-BY-NC-ND 4.0 International license .

1674

1675

1676

1677

1678

1679

1680

1681

1682

1683

1684

1685

1686

1687

1688

1689

1690

1691

1692

1693

1694

1695

1696

1697

1698

1699

1700

1701

1702

1703

1704

1705

1706

1707

1708

1709

1710

1711

1712

1713

1714

1715

1716

1717

1718

1719

1720

1721

1722
156. Yang, Q.E. et al. Environmental dissemination of mcr-1 positive Enterobacteriaceae by Chrysomya spp. (common blowfly): An increasing public health risk. Environ Int 122, 281-290 (2019).

157. Agnoletti, F., Brunetta, R., Bano, L., Drigo, I. \& Mazzolini, E. Longitudinal study on antimicrobial consumption and resistance in rabbit farming. Int J Antimicrob Agents 51, 197 205 (2018).

158. Malhotra-Kumar, S. et al. Colistin-resistant Escherichia coli harbouring mcr-1 isolated from food animals in Hanoi, Vietnam. Lancet Infect Dis 16, 286-287 (2016).

159. World Health Organization Stop using antibiotics in healthy animals to prevent the spread of antibiotic resistance. World Health Organization Media Center. http://www. who. int/mediacentre/news/releases/2017/antibiotics-animalseffectiveness/en (2017).

160. Randall, L.P. et al. Longitudinal study on the occurrence in pigs of colistin-resistant Escherichia coli carrying mcr-1 following the cessation of use of colistin. J App/ Microbiol 125, 596-608 (2018).

161. Haenni, M., Métayer, V., Gay, E. \& Madec, J.Y. Increasing Trends in mcr-1 Prevalence among Extended-Spectrum- $\beta$-Lactamase-Producing Escherichia coli Isolates from French Calves despite Decreasing Exposure to Colistin. Antimicrob Agents Chemother 60, 6433-6434 (2016).

162. Skov, R.L. \& Monnet, D.L. Plasmid-mediated colistin resistance (mcr-1 gene): three months later, the story unfolds. Euro Surveill 21, 30155 (2016).

163. Yang, Y.Q. et al. Co-occurrence of mcr-1 and ESBL on a single plasmid in Salmonella enterica. J Antimicrob Chemother 71, 2336-2338 (2016).

164. Gröndahl-Yli-Hannuksela, K. et al. The first human report of mobile colistin resistance gene, mcr-1, in Finland. Apmis 126, 413-417 (2018).

165. Henig, $\mathrm{O}$. et al. Identification of four patients with colistin-resistant Escherichia coli containing the mobile colistin resistance mcr-1 gene from a single health system in Michigan. Infect Control Hosp Epidemiol 40, 1059-1062 (2019).

166. Wang, Y. et al. Prevalence, risk factors, outcomes, and molecular epidemiology of mcr-1positive Enterobacteriaceae in patients and healthy adults from China: an epidemiological and clinical study. Lancet Infect Dis 17, 390-399 (2017).

167. Lu, X. et al. Epidemiologic and genomic insights on mcr-1-harbouring Salmonella from diarrhoeal outpatients in Shanghai, China, 2006-2016. EBioMedicine 42, 133-144 (2019).

168. Zhang, X.F. et al. Possible Transmission of mcr-1-Harboring Escherichia coli between Companion Animals and Human. Emerg Infect Dis 22, 1679-1681 (2016).

169. Hryhorowicz, M., Lipiński, D., Zeyland, J. \& Słomski, R. CRISPR/Cas9 immune system as a tool for genome engineering. Archivum immunologiae et therapiae experimentalis 65, 233-240 (2017).

170. Dong, H., Xiang, H., Mu, D., Wang, D. \& Wang, T. Exploiting a conjugative CRISPR/Cas9 system to eliminate plasmid harbouring the mcr-1 gene from Escherichia coli. Int J Antimicrob Agents 53, 1-8 (2019).

171. Wang, P. et al. Eliminating mcr-1-harbouring plasmids in clinical isolates using the CRISPR/Cas9 system. J Antimicrob Chemother 74, 2559-2565 (2019).

172. He, Y.Z. et al. A transposon-associated CRISPR/Cas9 system specifically eliminates both chromosomal and plasmid-borne mcr-1 in Escherichia coli. Antimicrob Agents Chemother, Aac0105421 (2021).

173. Sun, L. et al. Generation of Newly Discovered Resistance Gene mcr-1 Knockout in Escherichia coli Using the CRISPR/Cas9 System. J Microbiol Biotechnol 27, 1276-1280 (2017).

174. Zhao, C. et al. In vitro activities of Eravacycline against 336 isolates collected from 2012 to 2016 from 11 teaching hospitals in China. BMC Infect Dis 19, 508 (2019). 
medRxiv preprint doi: https://doi.org/10.1101/2022.02.28.22271560; this version posted March 1, 2022. The copyright holder for this preprint (which was not certified by peer review) is the author/funder, who has granted medRxiv a license to display the preprint in perpetuity.

It is made available under a CC-BY-NC-ND 4.0 International license .

1723

1724

1725

1726

1727

1728

1729

1730

1731

1732

1733

1734

1735

1736

1737

1738

1739

1740

1741

1742

1743

1744

1745

1746

1747

1748

1749

1750

1751

1752

1753

1754

1755

1756

1757

1758

1759

1760

1761

1762

1763

1764

1765

1766

1767

1768

1769

1770

1771

1772

1773
175. Denervaud-Tendon, V., Poirel, L., Connolly, L.E., Krause, K.M. \& Nordmann, P. Plazomicin activity against polymyxin-resistant Enterobacteriaceae, including MCR-1-producing isolates. J Antimicrob Chemother 72, 2787-2791 (2017).

176. Gerstmans, H., Rodríguez-Rubio, L., Lavigne, R. \& Briers, Y. From endolysins to Artilysin ${ }^{\circledR} \mathrm{S}$ : novel enzyme-based approaches to kill drug-resistant bacteria. Biochemical Society Transactions 44, 123-128 (2016).

177. Schirmeier, E. et al. Inhibitory and bactericidal effect of Artilysin $\left({ }^{\circledR}\right)$ Art-175 against colistinresistant mcr-1-positive Escherichia coli isolates. Int J Antimicrob Agents 51, 528-529 (2018).

178. Drider, D., Bendali, F., Naghmouchi, K. \& Chikindas, M.L. Bacteriocins: not only antibacterial agents. Probiotics and antimicrobial proteins 8, 177-182 (2016).

179. van der Weide, H. et al. Antimicrobial activity of two novel antimicrobial peptides AA139 and SET-M33 against clinically and genotypically diverse Klebsiella pneumoniae isolates with differing antibiotic resistance profiles. International journal of antimicrobial agents 54, 159166 (2019).

180. Dobias, J., Poirel, L. \& Nordmann, P. Cross-resistance to human cationic antimicrobial peptides and to polymyxins mediated by the plasmid-encoded MCR-1? Clin Microbiol Infect 23, 676.e671-676.e675 (2017).

181. Napier, B.A. et al. Clinical use of colistin induces cross-resistance to host antimicrobials in Acinetobacter baumannii. MBio 4, e00021-00013 (2013).

182. Guachalla, L.M. et al. Retained Activity of an O25b-Specific Monoclonal Antibody against an Mcr-1-Producing Escherichia coli Sequence Type 131 Strain. Antimicrob Agents Chemother 62 (2018).

183. Nezhadi, J. et al. Peptide nucleic acid-mediated re-sensitization of colistin resistance Escherichia coli KP81 harboring mcr-1 plasmid. Microb Pathog 135, 103646 (2019).

184. Daly, S.M., Sturge, C.R., Felder-Scott, C.F., Geller, B.L. \& Greenberg, D.E. MCR-1 Inhibition with Peptide-Conjugated Phosphorodiamidate Morpholino Oligomers Restores Sensitivity to Polymyxin in Escherichia coli. mBio 8 (2017).

185. Zhou, Y. et al. Discovery of a potential MCR-1 inhibitor that reverses polymyxin activity against clinical mcr-1-positive Enterobacteriaceae. J Infect 78, 364-372 (2019).

186. Guo, Y. et al. Honokiol Restores Polymyxin Susceptibility to MCR-1-Positive Pathogens both In Vitro and In Vivo. Appl Environ Microbiol 86 (2020).

187. Lu, N. et al. Isoalantolactone restores the sensitivity of gram-negative Enterobacteriaceae carrying MCR-1 to carbapenems. J Cell Mol Med 24, 2475-2483 (2020).

188. Liu, X., Sun, X., Deng, X., Lv, X. \& Wang, J. Calycosin enhances the bactericidal efficacy of polymyxin B by inhibiting MCR-1 in vitro. J App/ Microbiol 129, 532-540 (2020).

189. Wang, Y.M., Kong, L.C., Liu, J. \& Ma, H.X. Synergistic effect of eugenol with Colistin against clinical isolated Colistin-resistant Escherichia coli strains. Antimicrob Resist Infect Control 7, 17 (2018).

190. Dos Santos, A., da Silva, M.F., de Araújo-Júnior, J.X. \& da Silva-Júnior, E.F. Revealing Insights into Natural Products Against mcr-1-Producing Bacteria. Curr Drug Targets (2021).

191. Baron, S.A. \& Rolain, J.M. Efflux pump inhibitor CCCP to rescue colistin susceptibility in mcr-1 plasmid-mediated colistin-resistant strains and Gram-negative bacteria. J Antimicrob Chemother 73, 1862-1871 (2018).

192. Osei Sekyere, J. \& Amoako, D.G. Carbonyl cyanide m-chlorophenylhydrazine (CCCP) reverses resistance to colistin, but not to carbapenems and tigecycline in multidrug-resistant Enterobacteriaceae. Frontiers in microbiology 8, 228 (2017).

193. Okdah, L. et al. New therapy from old drugs: synergistic bactericidal activity of sulfadiazine with colistin against colistin-resistant bacteria, including plasmid-mediated colistin-resistant mcr-1 isolates. Int J Antimicrob Agents 51, 775-783 (2018).

194. Zhang, Y. et al. Synergistic Effect of Colistin Combined with PFK-158 against ColistinResistant Enterobacteriaceae. Antimicrob Agents Chemother 63 (2019). 
medRxiv preprint doi: https://doi.org/10.1101/2022.02.28.22271560; this version posted March 1, 2022. The copyright holder for this preprint (which was not certified by peer review) is the author/funder, who has granted medRxiv a license to display the preprint in perpetuity.

It is made available under a CC-BY-NC-ND 4.0 International license .

1774

1775

1776

1777

1778

1779

1780

1781

1782

1783

1784

1785

1786

1787

1788

1789

1790

1791

1792

1793

1794

1795

1796

1797

1798

1799

1800

1801

1802

1803

1804

1805

1806

1807

1808

1809

1810

1811

1812

1813

1814

1815
195. Chow, W.A., Jiang, C. \& Guan, M. Anti-HIV drugs for cancer therapeutics: back to the future? The lancet oncology 10, 61-71 (2009).

196. Elwell, L.P. et al. Antibacterial activity and mechanism of action of 3'-azido-3'deoxythymidine (BW A509U). Antimicrobial agents and chemotherapy 31, 274-280 (1987).

197. Peyclit, L., Baron, S.A., Yousfi, H. \& Rolain, J.M. Zidovudine: A salvage therapy for mcr-1 plasmid-mediated colistin-resistant bacterial infections? Int J Antimicrob Agents 52, 11-13 (2018).

198. Hu, Y., Liu, Y. \& Coates, A. Azidothymidine Produces Synergistic Activity in Combination with Colistin against Antibiotic-Resistant Enterobacteriaceae. Antimicrob Agents Chemother 63 (2019).

199. Stokes, J.M. et al. Pentamidine sensitizes Gram-negative pathogens to antibiotics and overcomes acquired colistin resistance. Nature microbiology 2, 1-8 (2017).

200. Barker, W.T. et al. Small molecule adjuvants that suppress both chromosomal and mcr-1 encoded colistin-resistance and amplify colistin efficacy in polymyxin-susceptible bacteria. Bioorg Med Chem 25, 5749-5753 (2017).

201. Tyrrell, J.M., Aboklaish, A.F., Walsh, T.R., Vaara, T. \& Vaara, M. The polymyxin derivative NAB739 is synergistic with several antibiotics against polymyxin-resistant strains of Escherichia coli, Klebsiella pneumoniae and Acinetobacter baumannii. Peptides 112, 149-153 (2019).

202. Li, Y. et al. Synergistic Antimicrobial Activity of Colistin in Combination with Rifampin and Azithromycin against Escherichia coli Producing MCR-1. Antimicrob Agents Chemother 62 (2018).

203. Yu, Y. et al. Novel partners with colistin to increase its in vivo therapeutic effectiveness and prevent the occurrence of colistin resistance in NDM- and MCR-co-producing Escherichia coli in a murine infection model. J Antimicrob Chemother 74, 87-95 (2019).

204. Zhou, Y.F. et al. Increased activity of colistin in combination with amikacin against Escherichia coli co-producing NDM-5 and MCR-1. J Antimicrob Chemother 72, 1723-1730 (2017).

205. Zhou, Y.F. et al. Activity of Tigecycline or Colistin in Combination with Zidovudine against Escherichia coli Harboring tet(X) and mcr-1. Antimicrob Agents Chemother 65 (2020).

206. MacNair, C.R. et al. Overcoming mcr-1 mediated colistin resistance with colistin in combination with other antibiotics. Nat Commun 9, 458 (2018).

207. Bulman, Z.P. et al. Polymyxin Combinations Combat Escherichia coli Harboring mcr-1 and bla(NDM-5): Preparation for a Postantibiotic Era. mBio 8 (2017).

208. Carpenter, J. et al. Activity of imipenem/relebactam against carbapenemase-producing Enterobacteriaceae with high colistin resistance. J Antimicrob Chemother 74, 3260-3263 (2019).

209. Stojanoski, V. et al. Structure of the catalytic domain of the colistin resistance enzyme MCR1. BMC biology 14, 1-10 (2016).

210. Ma, G., Zhu, Y., Yu, Z., Ahmad, A. \& Zhang, H. High resolution crystal structure of the catalytic domain of MCR-1. Scientific reports 6, 1-7 (2016). 
medRxiv preprint doi: https://doi.org/10.1101/2022.02.28.22271560; this version posted March 1, 2022. The copyright holder for this preprint (which was not certified by peer review) is the author/funder, who has granted medRxiv a license to display the preprint in perpetuity.

It is made available under a CC-BY-NC-ND 4.0 International license .

977 Records identified through database search between 2015 - July 2021

924 Records after duplications removed

850 Records screened against Abstract

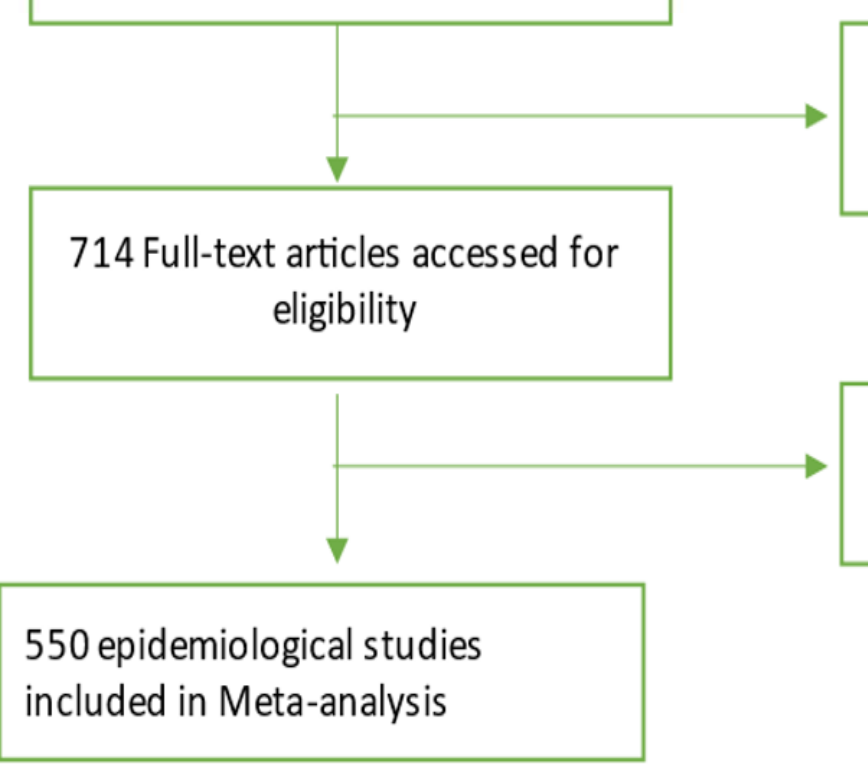

74 Records (Reviews, case reports, diagnostics, surveillance, Pharmacodynamics, a nonEnterobacteriaceae and non -related antibiotics studies) were moved

136 abstracts did not meet inclusion criteria

638 Studies included in Systematic review

1819 Figure 1. Flow diagram of literature search strategy and methodology. Out of 977 identified 1820 records between 2015 and 2021, a total of 638 studies were included in the systematic review whilst 550 of this were used for the epidemiological analyses. 
a

$$
300
$$

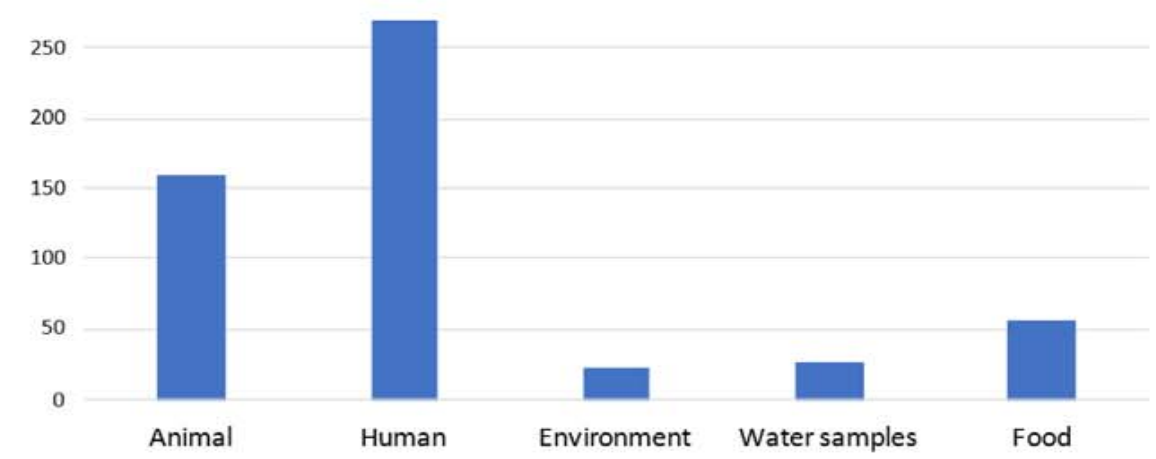

C

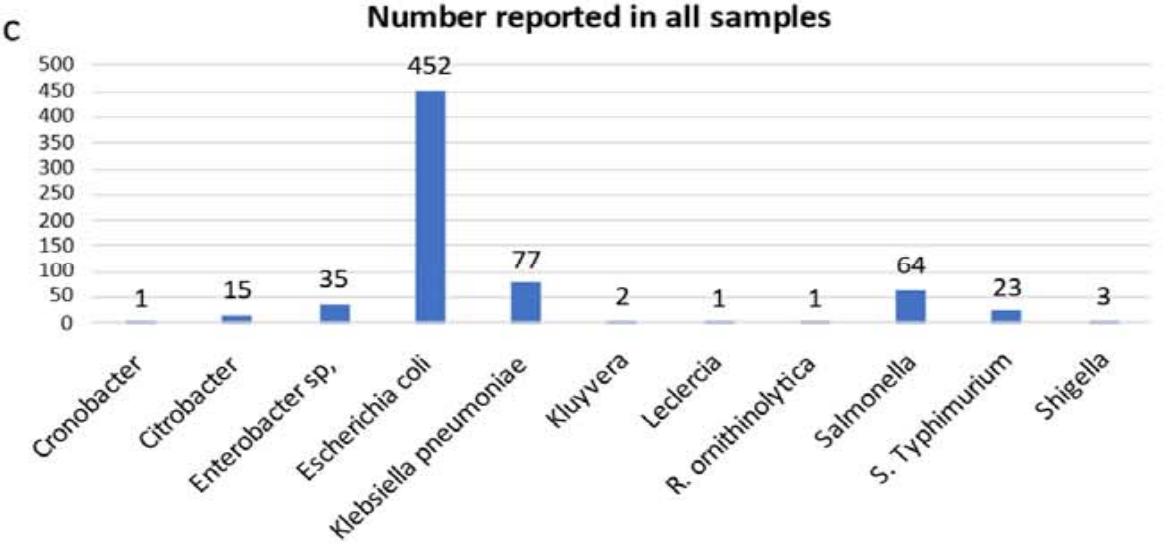

Number reported in all samples b

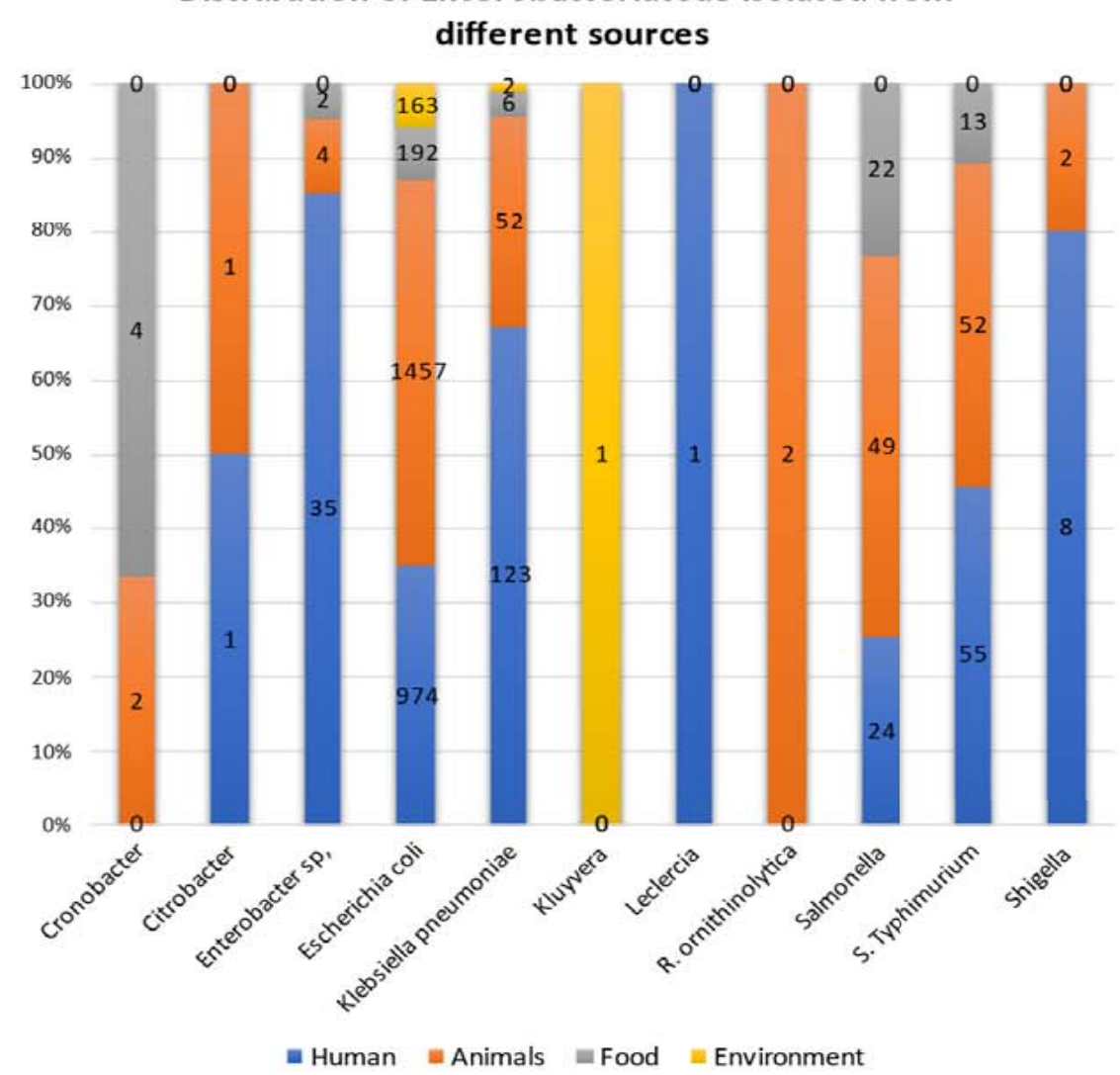
positive Enterobacteriaceae isolates were mainly animals, humans, water, food, and environmental samples. B) Distribution of $m c r$-producing Enterobacteriaceae species per sample source. C) The number of reports for each $m c r$-positive Enterobacteriaceae species. 


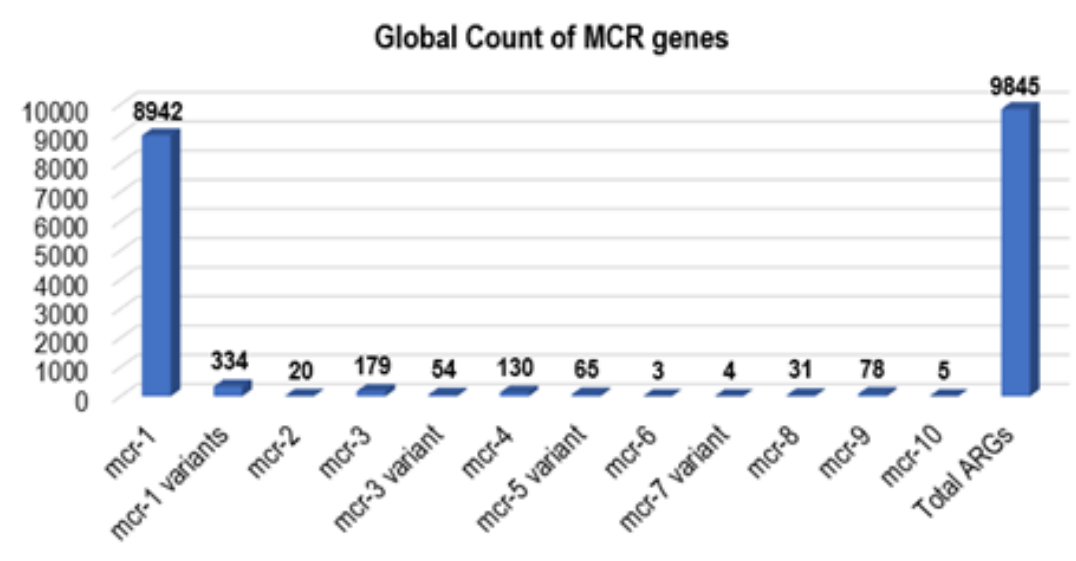

MCR variants distribution per country

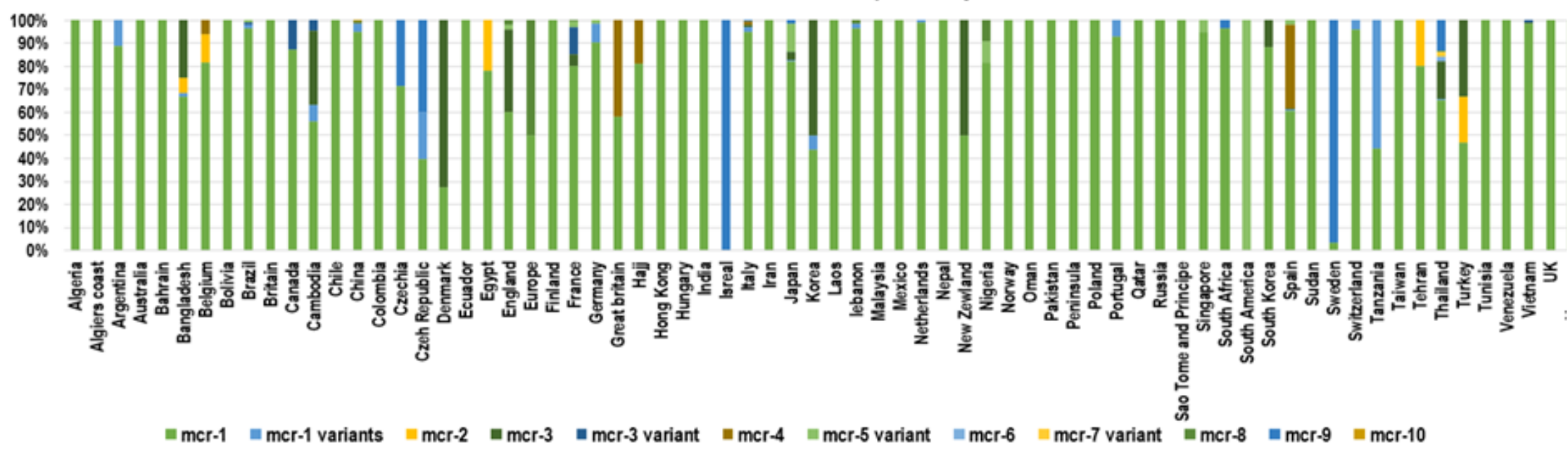

Figure 3. Global distribution and total count of mcr genes. A) Total number of mcr genes reported globally. B) The distribution of mcr genes per 


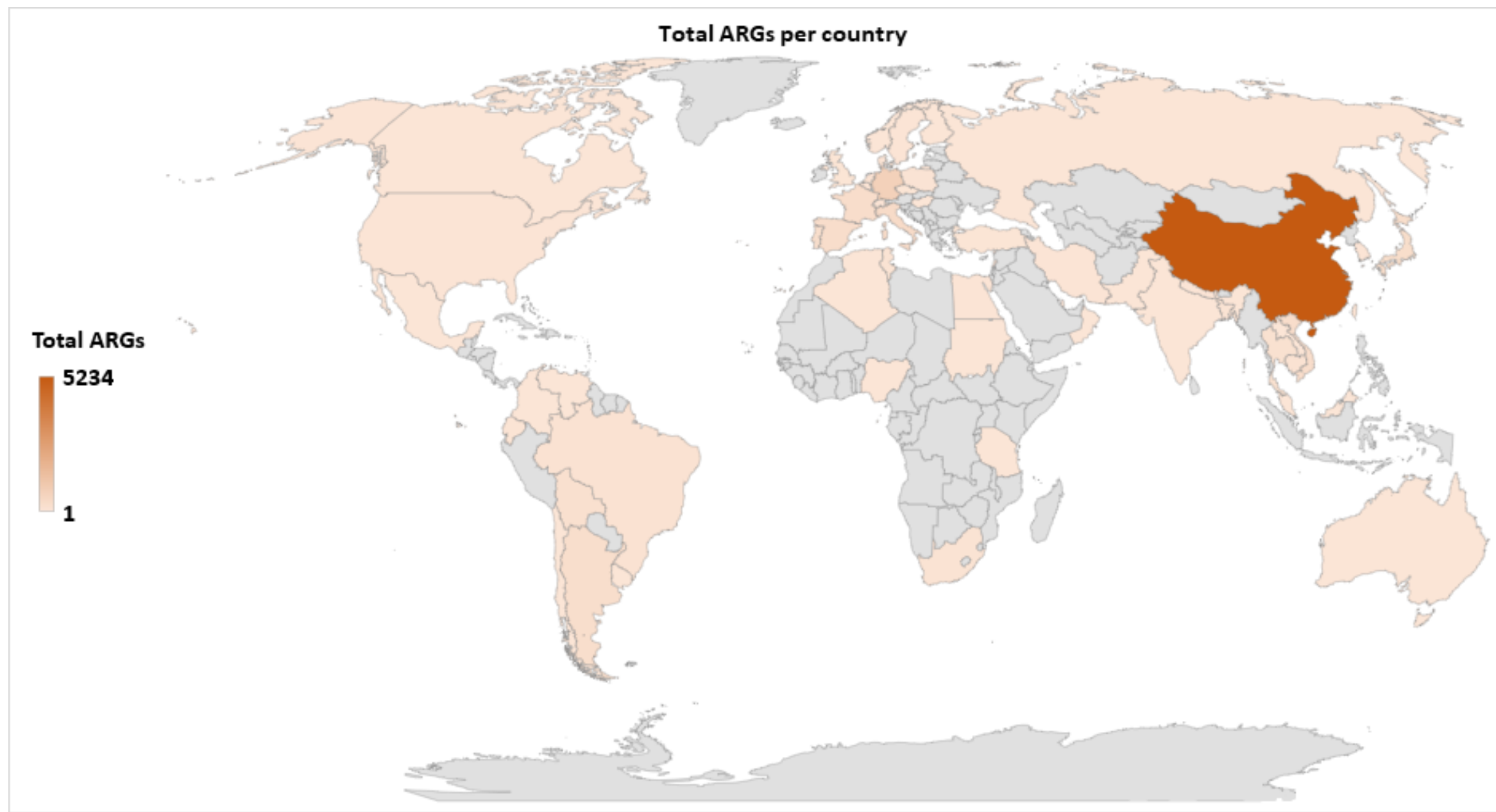




\section{Plasmid types associated with MCR variants}

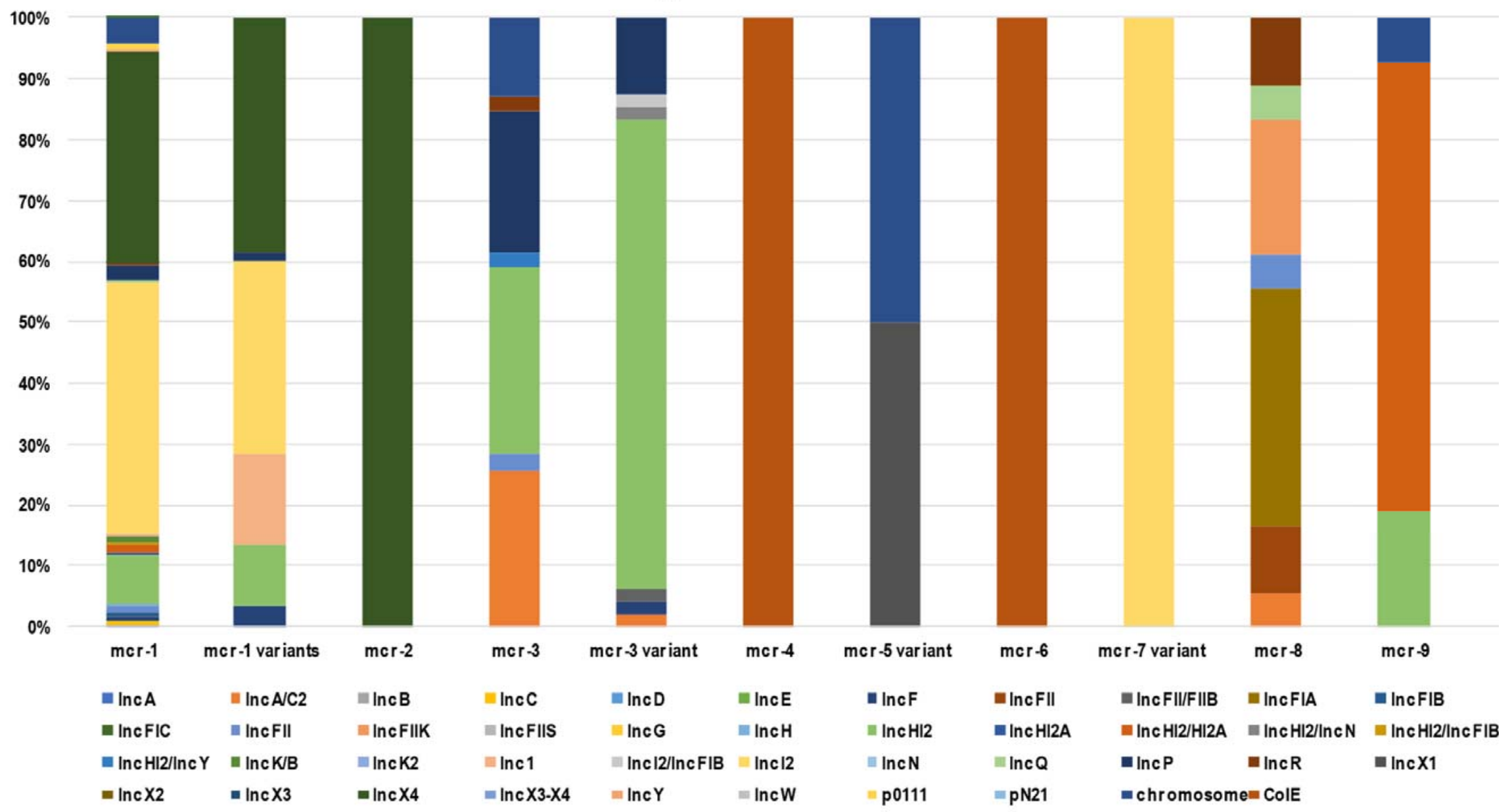



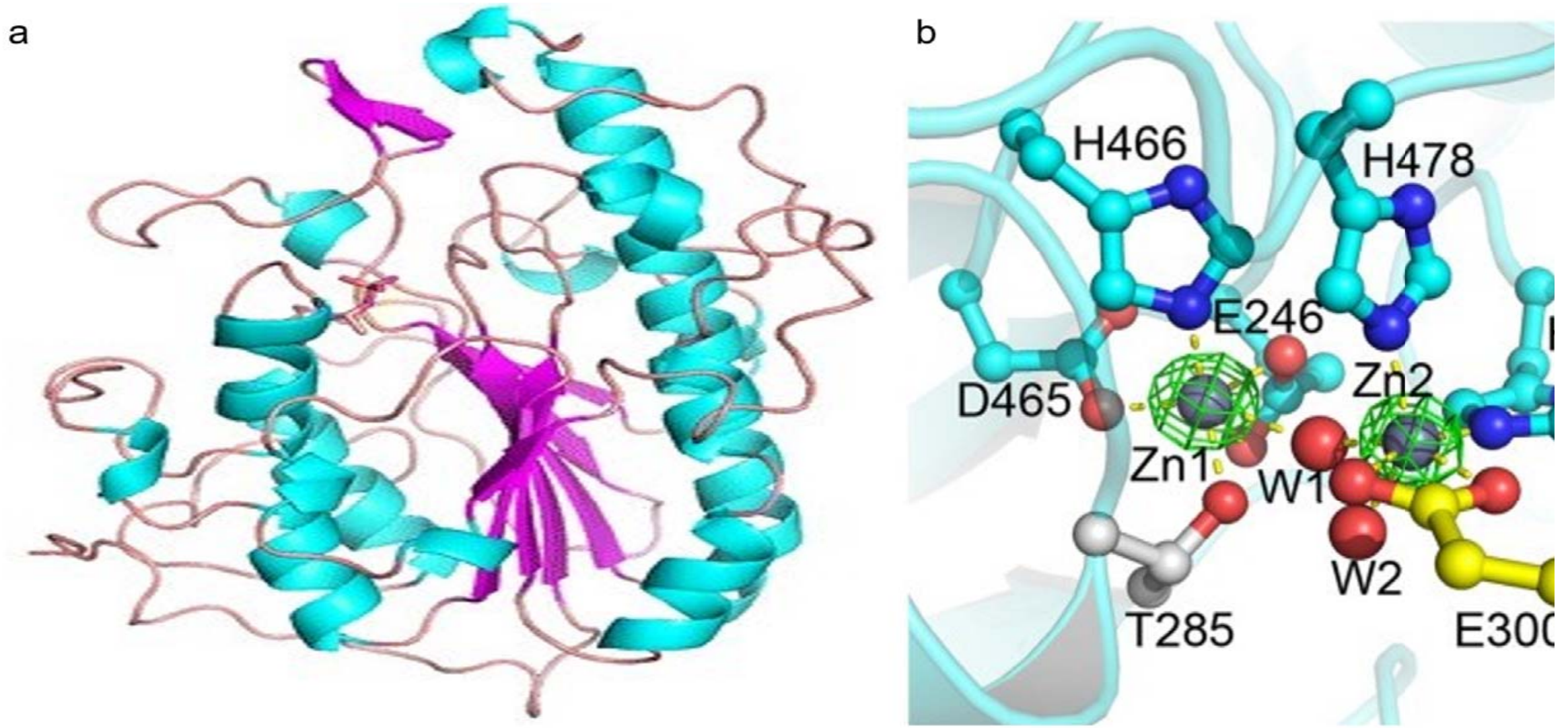

1833

1834

1835

1836

1837

1838

Figure 6. Structure of the catalytic domain of the MCR-1 protein and the five important residues required for its catalytic activity. A) The MCR1 's hemispherical shape composed of the $\beta-\alpha-\beta$ fold made up of helices (cyan), strands (purple) and loops (salmon). Image was obtained from Stojanoski et al. (2016) ${ }^{209}$. B) A ball and stick model showing the conserved active site residues of MCR-1 consisting of Asp (D)465, Glu (E)246, His (H)466, His(H)395 and Thr (T)285, coordinated to the zinc ions (Zn1 and Zn2) and water molecules (W1 and W2). Image was obtained from Ma et al. (2016) ${ }^{210}$. 

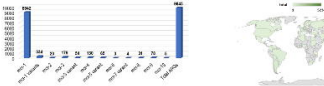

W.F wrores don bet wotioifry

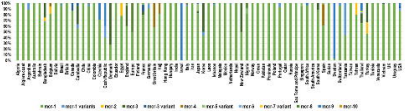




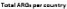

Tatal anat

9 24

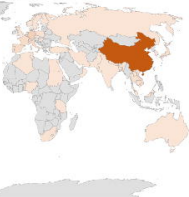

